Мареев В. Ю., ${ }^{1,2}$ Орлова Я.А. ${ }^{1,2}$, Павликова Е. П., ${ }^{1,2}$, Акопян Ж. А. ${ }^{1,2}$, Мацкеплишвили С. Т. ${ }^{1}$ Пиисюк А. Г. ${ }^{1,2}$, Середенина Е. М. ${ }^{1,2}$, Потапенко А. В. ${ }^{1,2}$, Мамахов П. С. ${ }^{1}$, Самоходская М. М. ${ }^{1,2}$, Мершина Е.А. ${ }^{1,2}$, Синицин В.Е. ${ }^{1,2}$, Асратян А.А. ${ }^{1}$, ЖАанова Е.А. ${ }^{1,2}$, Мареев Ю. В., ${ }^{3,4}$, Беграмбекова Ю. $\Lambda .{ }^{1,2}$, Шатохина Е.А. ${ }^{1}$, Камалов А. А. ${ }^{1,2}$

1 «Медицинский научно образовательный центр МГУ имени М. В. Аомоносова», Москва, Россия

${ }^{2}$ МГУ имени М. В. Аомоносова, Факультет фундаментальной медицины, Москва, Россия

3 «Национальный меАицинский исследовательский центр терапии и профилактической меАицины», Москва, Россия

4 «Робертсоновский центр биостатистики», Университет ГАазго, Великобритания

\title{
УПРЕЖААЮЩАЯ ПРОТИВОВОСПААИТЕАЬНАЯ
}

\section{И АНТИКОАГУАЯНТНАЯ ТЕРАПИЯ В АЕЧЕНИИ ПРОАВИНУТЫХ СТААИЙ НОВОЙ КОРОНАВИРУСНОЙ ИНФЕКЦИИ (COVID-19). РАЗБОР КАИНИЧЕСКИХ САУЧАЕВ И АИЗАЙН ИССАЕАОВАНИЯ: КОАХИЦИН ПРОТИВ РУКСОАИТИНИБА И СЕКУКИНУМАБА В ОТКРЫТОМ ПРОСПЕКТИВНОМ РАНАОМИЗИРУЕМОМ ИССАЕАОВАНИИ У ПАЦИЕНТОВ С COVID-19 (КОАОРИТ)}

\begin{abstract}
Статья посвящена вопросу эффективного мечения новой коронавирусной инфекции (COVID-19) на продвинутых стаАиях болезни. Рассматриваются типы ответа системы иммунитета на вирусную нагрузку SARS-CoV-2 с запуском процесса воспаления. Подробно анализируется ситуация, при которой нарастающее аутоиммунное воспаление (вплоть Ао развития «цитокинового шторма») поражает не только мегочную паренхиму, но и энАотелий мелких сосудов Аегких. ОАновременное поражение альвеол и микротромбоз сосудов мегких сопровожАаются прогрессирующим нарушением газообмена, развитием острого респираторного Аистресс-синдрома, мечение которого, Ааже с использованием инвазивной вентиляции мегких, малоэффективно и не позволяет реально менять прогноз больных с COVID-19. C целью прерывания патологического процесса на наиболее ранних стадиях болезни обосновывается необходимость упреждающей противовоспалительной терапии в сочетании с активным антикоагумяционным мечением. Разбираются результаты первых рандомизированных исследований по применению ингибиторов провоспалительных цитокинов и хемокинов - интерлейкина-6 (тоцилизумаба), интерлейкина-17 (секукинумаба), блокаторов янус-киназ, через которые передается сигнал на клетки (руксолитиниб), имеющих потенциал в раннем мечении COVID-19. В качестве оригинального пути рассматривается применение известного противовоспалительного препарата Аля мечения подагры колхицина у больных с COVID-19. Приводится Аизайн оригинального сравнительного исследования КОАОРИТ по применению колхицина, руксолитиниба и секукинумаба в мечении COVID-19. На примере клинических наблюАений из практики работы Университетской клиники МНОЦ МГУ имени М.В. Аомоносова анализируется опыт эффективной ранней противовоспалительной терапии вместе с антикоагулянтами пациентов с COVID-19 и опасности, связанные с отказом от своевременного начаца такой терапии.
\end{abstract}

Ключевые слова

Аля циитирования

Автор дия переписки
COVID-19; цитокиновый шторм; комхицин; руксолитиниб; секукинумаб; противовоспалительная терапия; антикоагумянтная терапия

MareevV.Yu., Orlova Ya. A., Pavlikova E. P., Akopyan Z. A., Matskeplishvili S. T., Plisyk A. G. et al. Proactive antiinflammatory and anticoagulant therapy in the treatment of advanced stages of novel coronavirus infection (COVID-19). Case Series and Study Design: COLchicine versus ruxolitinib and secukinumab in Open prospective RandomIzed Trial (COLORIT). Kardiologiia. 2020;60(9):4-21. [Russian: Мареев В. Ю., Орлова Я.А., Павликова Е. П., Акопян Ж.А., Мацкеплишвили С. Т., Плисюк А. Г. и Ар. УпрежАающая противовоспалительная и антикоагулянтная терапия в кечении продвинутых стадий новой коронавирусной инфекции (COVID-19). Разбор клинических случаев и дизайн исследования: КОАхицин прОтив Руксолитиниба И секукинумаба в оТкрытом проспективном рандомизируемом исследовании у пациентов с COVID-19 (КОАОРИТ). КарАиология. 2020;60(9):4-21].

Беграмбекова Юлия Аеоновна. E-mail: julia.begrambekova@ossn.ru
П родолжающийся рост числа случаев новой коронавирусной инфекции (COVID-19) в мире, смертность около 4\%, колоссальные сложности мечения больных с тяжелой Авусторонней вирусной пневмонией требуют рациональных подходов к терапии этого забомевания на разных этапах его развития. Среди инфици- рованных вирусом SARS-CoV-2 около $40 \%$ имеют бессимптомное вирусоносительство, еще около $25 \%$ - кегкое неосложненное течение инфекции и не нуждаются в госпитализации [1]. ОАнако у трети пациентов инфекция протекает с осложнениями в виде развития специфической вирусной пневмонии, что требует поиска эффек- 
тивной терапии. СреАи больных со среАнетяжелым и тяжелым течением, мечащихся в стационаре, около 10\% требуют нахожАения в реанимации и $5 \%$ - инвазивной искусственной вентимяции мегких (ИВА). Смертность в стационаре Аостигает $10 \%$ и более, увеличиваясь с возрастом и количеством сопутствующих заболеваний [1].

В Университетской кминике МГУ за период с 21 апремя по 13 июня 2020 года было пролечено 424 пациента с коронавирусной пневмонией. В отАелении реанимации находилось 48 пациентов (11,3\%), на инвазивной ИВ 24 больных (50\% от реанимационных и 5,7\% от всех больных), что в целом соответствовало мировой статистике [2-4].

Из них умерло 4 пациента (0,94\%), средний возраст $78 \pm 8$ мет (72-86 мет), все с тремя и более сопутствующими заболеваниями. Необходимо сказать, что в связи с закрытием COVID-госпиталя в МНОЦ МГУ еще 10 пациентов были перевеАены в Аругие стационары, 5 из них умерло в Аругих клиниках. Самой пожилой из выписанных больных с Авусторонней пневмонией вирусной и бактериальной этиологии было 97 мет.

Схематично этапность течения новой коронавирусной инфекции показана на рисунке 1.

На первом этапе (показано синей минией на рисунке 1) главную негативную роль играет вирусная нагрузка, стартующая еще Ао появления первых симптомов инфекции, и именно она приводит к первому раннему пику метальности (конец первой недели болезни). Этот периоА наиболее опасен Аля больных пожилого и старческого возраста с повышенной массой тела, обремененных сопутствующими заболеваниями в виде сердечно-сосудистой патологии, сахарного диабета, заболеваний мегких и почек. Особенно плохой прогноз регистрируется у пациентов, прекращающих привычную терапию, прежде всего блокаторами ренин-ангиотензин-ацьдостероновой системы, статинами и современными гипогмикемическими препаратами, и не контролирующих оптимацьное артериальное Аавление (АA), хоместерин и глюкозу [5-7]. В этот периоА главное внимание удемяется наиболее раннему применению противовирусных препаратов и $е$ карств, препятствующих проникновению вируса в клетку, чему была посвящена специальная статья [8].

В этой статье мы проанализируем попытки прибмизиться к оптимальному комбинированному мечению новой коронавирусной инфекции на продвинутых этапах ее развития, когАа главным становится применение противовоспалитемьной терапии и антикоагулянтов.

После 7-10-го Аня болезни все возрастающую роль в прогрессировании инфекции и плохом прогнозе больных начинают играть Аругие (кроме вирусемии) факторы. Если при видимом благополучии, незначительном снижении сатурации кислорода, в этот период болезни
Рисунок 1. Схема прогрессирования размичных проявмений новой коронавирусной инфекции по Аням болезни

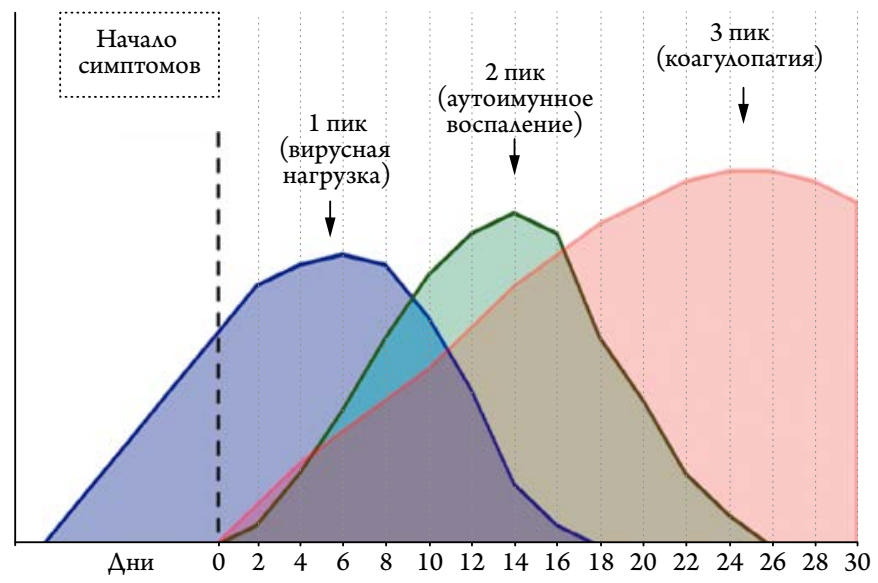

сохраняется субфебрилитет, не проходит чувство нехватки воздуха, астении и, главное, сохраняется или прогрессирует мимфопения, имеется Ааже некритическое повышение С-реактивного белка (С-РБ) и интерлейкина-6 (ИА-6), необходимо жАать прогрессирования инфекции. Как следует из рисунка 1, в это время начинают играть веАущую роль Аругие факторы: постепенно нарастающее воспаление (зеленая миния), которое приводит к перенапряжению иммунной системы, резкому увекичению выработки цитокинов, стимулирующих развитие инфильтративного фиброза, экссуАативного поражения мегочной ткани, Аесквамации мегочных эпителиальных клеток с потерей воздушности альвеол [9]. Это состояние больше напоминает развитие альвеолита, чем истинной пневмонии, альвеолы «тонут», мегкие теряют свою способность к газообмену. Аегочная ткань становится безвозАушной, с выраженным отеком и участками ателектазов [10]. В таких случаях Ааже перевод пациентов на ИВ $\Lambda$ не может решить проблемы.

На рисунке 2 представлены типы реакций иммунной системы и воспакения при развивающейся новой коронавирусной инфекции, опосреАованные цитокинами.

Как виАно, нормальный иммунный ответ (синяя $\Lambda$ ния на рисунке 2) позвомяет организму постепенно справиться с нарастающим воспалением. Наибольший риск приходится на 10-14-е Ани болезни $[11,12]$. Аля относительно молодых пациентов без сопутствующих забомеваний это может закончиться умеренным поражением мегочной ткани (1-2-й стадии по классификации Министерства зАравоохранения Российской Федерации (МЗ РФ)) виде матовых стекол, когда воздушность снижена, но альвеолы способны к газообмену [13]. Эти больные обычно могут справиться с инфекцией без противовоспалительной терапии, но риск развития пневмонии полностью исключить нельзя $[14,15]$. Хотя и у них ранняя противовоспалительная терапия помогает быстрее пода- 
Рисунок 2. Аутоиммунное воспаление при COVID-19 и возможности противовоспалительной терапии (объяснения в тексте)

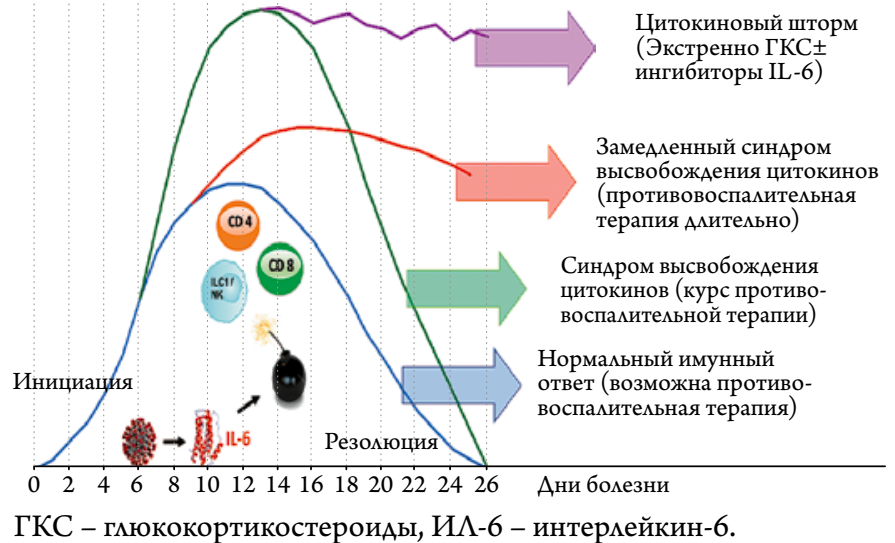

вить инфекцию и избежать Алительного периода астении и «выхода» из болезни. Аетальность у таких больных менее $1 \%$, как при сезонном гриппе.

При грозных симптомах продолжающегося воспамения, отсутствии укучшения к 10-му Аню забомевания возможен экстремахьно высокий иммунный ответ (земеная миния на рисунке 2), получивший название «синАром высвобожАения цитокинов» $[14,16]$. Происходит быстрое (иногда моментальное) прогрессирование поражения мегочной ткани в виде «бумыжной мостовой», то есть неравномерного уплотнения различных участков матовых стекол с переходом в консолидацию, что свиАетельствует о постепенной потере воздушности [17]. При аутопсии умерших от COVID-19 в зонах консолиАации выявлялся цемлюлярный фибро-миксоиАный экссудат [18]. Таким пациентам необходима экстренная упрежАающая противовоспалительная терапия, позвомяющая Аостаточно быстро в течение 5-7 Аней «перемомить» ситуацию и не Аопустить попадания больных в ОРИТ и перевода на ИВА, что и Аолжно быть целью мечения COVID-19. Существенную помощь оказывает постоянная кислородная поААержка, максимально Алительное нахожАение больных в «прон» позиции и аккуратное начало Аыхатемьной гимнастики, что активно использовалось в практике работы МНОЦ МГУ [19].

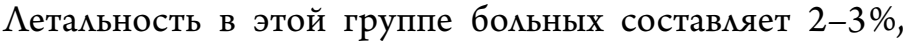
и может быть снижена своевременным начамом противовоспалительного мечения. Наиболее неблагоприятными Анями явмяется конец второй - начало третьей неАеми болезни (красная миния на рис. 1).

У больных пожилого и старческого возраста, особенно у мужчин с повышенной массой тела, сахарным Аиабетом, ССЗ и мегочными заболеваниями возможно и неблагоприятное течение болезни $[20,21]$. Эта ситуация определяется как «замеАленный синдром высвобожАе- ния цитокинов» и показано красной минией на рис. 2. Активация ИА-6 и Аругих провоспалительных цитокинов и хемокинов в ответ на проникновение вируса SARS-CoV-2 в эпителиальные альвеолярные клетки привоАит к бурной стимумяция мимфоцитов CD-4 и CD-8, в качестве защитной реакции [22]. Это сопровожАается появцением мимфопении, степень которой наиболее точно предсказывает тяжесть течения болезни и Ааже прогноз больных [23]. В очагах поражения (мелкие бронхи и альвеолы) накапливаются гранулоциты в виле нейтрофильной и макроцитарной инфильтрации [16]. В крови кроме нарастающей мимфопении, оАновременно, регистрируется нейтрофилез. В этом случае и после 15 Аня заболевания неукмонно прогрессирует течение вирусной пневмонии в виде все большего объема поражения мегочной паренхимы, несмотря на все усимия [24]. У таких больных Ааже упрежАающая противовоспалительная терапия очень меАленно меняет ситуацию, на контрольных МСКТ Аолго сохраняется большой объем поражения [25]. Ао 4 недель Аержится одышка, низкая сатурация кислорода, астения, иногАа достигающая крайней степени выраженности. И зАесь необходима постоянная кисмородная терапия. По возможности нужно пытаться держать больных межа на животе, что позволяет увеличить глубину Аыхания и вентимяцию занних отАелов мегких Несмотря на это, ряд пациентов приходится поАвергать экстренной противовоспалительной терапии бцокаторами ИА-6 или глюкокортикостероилами (ГКС). ПеревоА их в отАеление Реанимации и интенсивной терапии (ОРИТ) и на ИВ А нереАко требует недели и больше механической вентимяции мегких. ЗАесь на первый план выходит мастерство реаниматологов, чтобы не допустить развития внутрибольничной инфекции. При первой же возможности пациенты Аолжны переводиться на неинвазивную вентимяцию мегких и самостоятельное дыхание, что также было принципиальным правилом работы Университетской клиники МГУ. В США и Европе около 14\% госпитализированных с COVID-19 требуют нахожАения в ОРИТ и $12,2 \%(!)-И В \Lambda$, что соответствует $80-$ 90\% от всех больных в реанимации при Алительности нахожАения на механической вентимяции мегких в среАнем 12-18 Аней [26-28]. Возможно, такая чрезмерно активная тактика мечения может опредемять более высокую смертность в сравнении с Китаем и Российской Федерацией. В целом метальность в этой группе больных Аостигает $10-15 \%$.

Наконец, критическое развитие событий в виде неукмонного прогрессирования аутоиммунного воспаления получило название цитокинового шторма (сиреневая миния на рисунке 2), протекающего с резкой активацией ИА-6 и Аругих провоспалительных цитокинов и хемокинов, кратным увеличением С-РБ, мимфопени- 
ей, нейтрофилезом и нарастающим острым респираторным Аистресс-синаромом (ОРАС) [29, 30]. В этом случае имеет место тотальное поражение обоих мег-

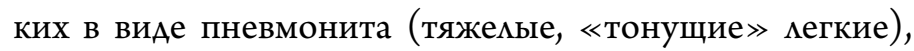
что клинически проявмяется нарастающим ОРАС и сопровождается неблагоприятным прогнозом больных с COVID-19 [10]. Эти пациенты вынужАены Алительно (Ао месяца и более) мечиться в ОРИТ, недемями находиться на ИВ $А$. НереАки осложнения в виде развития пневмоторакса или пневмомедиастинума $[31,32]$. Мы наблюдали 5 уникальных случаев спонтанных пневмотораксов и/ими пневмомеАиастинумов у критических пациентов на Алительной ИВ ального описания. В критических случаях Ааже максимально активная противовоспалительная терапия тоцилизумабом (казавшимся панацеей) и высокими дозами глюкокортикостероидов (ГКС) не всегАа позволяет прекратить прогрессирование инфекции и вылечить вирусную пневмонию [33]. Особенностью вируса SARSCoV-2 является способность поражать не только мегкие, но и Аругие органы и системы (серАце, почки, поАжелудочную железу и Ааже головной мозг) $[9,34,35]$. В этих случаях парамлельно с тяжелым ОРАС развивается и прогрессирует полиорганная неАостаточность в виАе развития миокарАита, сердечной недостаточности, почечной недостаточности, обострение течения сахарного Аиабета. У таких бомьных по мировой статистике метальность составмяет от 50-60 Ао 80-90\%, в зависимости от активности и Алитемьности ИВ $\Lambda[26,36]$. Третий пик смертности (красная миния на рисунке 1) приходится на 25-30-е Ани болезни.

Исходя из преАставленных вариантов прогрессирования болезни, необходимо помнить о клинических проявлениях заболевания, позволяющих преАсказать его неблагоприятное течение, и как можно раньше начать специфическую противовоспалительную терапию. К ним относятся: ухудшение клинического состояния в виде сохранения михораАки, не проходящая одышка и чувство заложенности в груди, иногАа изматывающий кашель, низкая сатурация кислорода, невозможность находиться без кислородной поААержки и прогрессирующая астения. Исходя из нашего опыта, упорная мимфопения, нейтрофилез, повышение С-РБ, и, особенно ИА-6, на второй неделе болезни являются грозным преАвестником прогрессирования вирусной пневмонии (пневмонита), что требует упреждающей противовоспамительной терапии.

Самым простым и информативным критерием, позволяющим различить больных с мегкой, среАнетяжелой и критической формами COVID-19, является содержа-

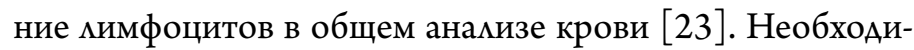
мо постоянное пристацьное внимание как к абсомютно- му их количеству, так и Аинамике в процессе наблюдения и мечения.

Хочется отметить, что есть Ава Аополнительных мегко вычисляемых показателя, наряду с крайне важной оценкой Аинамики числа Аимфоцитов, которые очень точно преАсказывают прогрессирование воспаления и опасность «срыва» пациентов с развитием прогрессирующего ОРАС. Первым из них является нейтрофильномимфоцитарный индекс (иН/ $\Lambda$ ), вычисляемый Аелением абсолютного количества нейтрофилов на количество мимфоцитов [37]. Этот показатель предсказывает не только выраженность воспаления, но и вероятность неблагоприятного клинического течения болезни уже при повышении выше $3[38,39]$. Этот индекс значимо прямо коррелирует с поражением мегких на мультиспиральной компьютерной томографии (МСКТ): $\mathrm{r}=0,823 ; \mathrm{p}<0,001$ [40]. Кроме того, повышение иН/ $\Lambda$ на каждую еАиницу увеличивает риск смерти пациентов с COVID-19 на 8\% и «опасным» отрезным уровнем можно считать 5 еАиниц [41]. Интересно, что векичина иН/ $\Lambda>10$ при поступлении в клинику незначимо повышает риск инвазивной ИВА и смерти, но такие показатели иН/ Аню мечения преАсказывают повышение необходимости инвазивной ИВ $\Lambda$ в 3,3 раза $(\mathrm{p}=0,008)$ и риск смерти в 11 раз $(\mathrm{p}<0,0001)$ [42]. Вторым очень уаобным показателем оценки тяжести воспаления, течения заболевания и прогноза больных с COVID-19 является отношение $и$ имоцитов к С-РБ (индекс $\Lambda / \mathrm{C}$, и $\Lambda / \mathrm{C}$ ), вычисляемое Аелением количества лимфоцитов (в тысячах) на показатель уровня С-РБ [43]. В Аанном случае, в отличие от иН/ $\Lambda$, чем выше показатель, тем кучше, и наоборот. При COVID-19 и /C >100 к 7-му Аню пребывания в стационаре снижает шансы на плохой прогноз на $80 \%$, $\mathrm{p}=0,001[42]$.

Проведение раннего (упрежАающего) противовоспалительного мечения Аолгое время не являлось рекомендованным. В итоге Ааже у молодых больных с внешне «благоприятным» началом болезни, в некоторых случаях стремительно прогрессировало поражение мегких. Именно в этих случаях контроль состояния больных (сохраняющаяся кихораАка, одышка, выраженная астения),

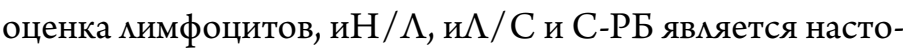
ятельно необходимым Аля принятия решения о своевременной интенсификации мечения. КажАый Аень промеАления чреват ухудшением прогноза пациентов, а картина поражения мегких на МСКТ нереАко «запаздывает» по сравнению с маркерами воспаления.

Попытка противовоспалительного мечения с блокаАой ИА-6 (тоцилизумаб или сарилумаб) в большинстве случаев запаздывает и проводится пациентам, уже находящимся на ИВ $\Lambda$, становясь «терапией отчаяния». Такое мечение было (и остается) во временных рекомендациях 
МЗ РФ [44]. Ретроспективные анамизы применения тоцилизумаба показали его эффективность в снижении Алительности вазопрессорной поААержки, без сокращения сроков Аостижения нормализации клинического состояния при COVID-19 [45]. В Аругих случаях зафиксировано сокращение времени Ао клинического улучшения больных с COVID-19, находящихся на ИВ $\Lambda$, но не пациентов без вентимяции мегких, и Ааже снижение смертности, но только в самых тяжелых группах больных [46]. В тщательно проведенном в Йельском университете исслеловании применение тоцилизумаба ассоциировалось с $45 \%$ снижением риска смерти и улучшением клинического состояния больных с COVID-19, но оно увеличивало риск суперинфекций (внутрибольничных пневмоний) с $26 \%$ Ао 54\%; p<0,001 [47]. Описаны связь терапии тоцикизумабом с развитием грибковой инфекции [48] и неэффективность его применения при нахичии сахарного Аиабета и гипергликемии [49]. Но, главное, что относительно небольшие рандомизированные клинические исследования Ао настоящего времени не подтверАили положительного влияния антицитокиновой терапии на прогноз больных с тяжелой COVID-19. В конце июля закончимось первое Аействительно крупное рандомизированное исследование COVACTA, включившее 450 больных с COVID-19. К сожалению, и в этом случае тоцилизумаб не вАиял на прогноз больных и их потребность в ИВ $\Lambda$, хотя несколько уменьшал время пребывания больных c COVID-19 в стационаре [50]. Бомее того, при мечении сарихумабом у пациентов с COVID-19 умеренной тяжести была тенденция к ухудшению [51]. Но исследования с этими препаратами продолжаются, в частности, в протоколе REMDACTA исслеАуется комбинация противовирусного препарата ремАесивира с тоцилизумабом [52], в исследованиях MARIPOSA [53] и EMPACTA [54] возможность использования тоцилизумаба в Аополнение к стандартному мечению коронавирусной пневмонии.

При отсутствии антагонистов ИА-6, рекомендованных МЗ РФ к использованию у критических пациентов, нам пришлось использовать метод пульстерапии высокими Аозами ГКС внутривенно, который позволял прервать нарастающее воспаление и не допускать развитие цитокинового шторма, уменьшать потребность в механической вентимяции мегких и Аобиваться стабилизации кминического состояния больных [55]. Сегодня стало очевиАно, что мы были правы, и в отсутствии Аругих возможностей терапия стероилами в мечении больных с COVID-19 вполне возможна. В крупном рандомизированном клиническом исслеАовании RECOVERY, включившем более 6400 пациентов с COVID-19, Аексаметазон (6 мг/с в течение 10 Аней) значимо на $17 \%$ снижах риск смерти, но если у пациентов на инвазивной механической вентиляции были Аостигнуты отмичные результаты, у не- тяжелых больных имелась тенденция к повышению риска смерти на 19\% [56]. Иными словами, повторимись результаты, полученные при мечении сарилумабом. В Аругом исслеАовании пульстерапия метилпреАнизолоном по 250 мг внутривенно в первые сутки и затем по 80 мг в течение еще пяти Аней плюс 8 мг / кг тоцилизумаба внутривенно у $43 \%$ пациентов значимо снижали риск нахожАения на ИВ $\Lambda$ и смерти на 65\% [57]. Несмотря на высокую эффективность, Аечение ГКС сопровожАалось явной тенАенцией к росту риска тромбоэмболий мегочной артерии (21\% против $11 \%, \mathrm{p}=0,059)$. Аналогично и в нашем исследовании ПУТНИК при хорошем клиническом эффекте и снижении С-РБ на фоне мечения ГКС отмечалось значимое повышение иН $/ \Lambda$, что отмечалось и Аругими исследователями [42]. В итоге протромботическое Аействие ГКС привоАило к риску развития тромботических и тромбоэмболических осложнений, что могло требовать активизации антикоагумянтной терапии и затягивать сроки выздоровления [55].

Отсутствие эффекта Ааже от агрессивной противовоспалительной и антицитокиновой терапии у тяжемых пациентов с «мистической» пневмонией при COVID-19 поставияо вопрос о возможных Аополнительных механизмах ее развития и прогрессирования. Степень повышения провоспалительных цитокинов и хемокинов у пациентов с COVID-19 оказалось в разы ниже, чем при ОРАС Аругой этиологии [58]. Поэтому, несмотря на широко используемый термин «цитокиновый шторм», не только воспаление определяет тяжесть течения этой бомезни. Третьим (кроме собственно вирусной инфекции и аутоиммунного воспаления), уникамьным механизмом развития и прогрессирования COVID-19 явмяется быстрое появмение коагулопатии и повышенного тромбообразования (коричневая миния на рисунке 1). Уже в ранних исследованиях в Китае было показано, что величина D-димера в многофакторных анализах определяла неблагоприятное течение болезни, повышенный риск ИВ $\Lambda$ и более высокую смертность [59-61]. Частота крупных венозных тромбозов и тромбоэмболий при COVID-19 колеблется от 20 Ао 35\%, что позволимо рассматривать эту вирусную инфекцию как протромботическую болезнь [62-65]. И в этом случае большую пользу может Аать оценка иН/ $\Lambda$, повышение которого выше 5,7 еАиниц увекичивает риск массивных тромбоэмболий в 10,8 раз и риск смерти [66]. В исследовании ПУТНИК мы обнаружили значимую прямую положитемьную корреляцию Аинамики иН $/ \Lambda$ с D-Аимером, а также с риском венозных тромбозов и тромбоэмболий [55].

Уникальной особенностью новой коронавирусной инфекщии явмяется повышенный риск микротромбозов мелких сосудов мегких, обнаруживаемый почти у 7080\% больных COVID-19 с тяжемой пневмонией [67-69]. 
Важно помнить, что чем тяжелее состояние пациентов, тем выше степень поражения сосудов мегких и выраженность коагулопатии, но подобные изменения регистрируются уже с самых ранних стаАий болезни $[70,71]$. При этом еще больше нарушается газообмен и бурно, буквально в течение 1-2 Аней, необратимо прогрессирует развитие ОРАС $[63,72]$. На аутопсии обнаруживаются множественные тромбозы мелких сосудов мегких, препятствующие Аиффузии кислорода из альвеол в кровоток $[10,12]$. Изменения в мегких очевидно трактуются как аутоиммунное поражение альвеол (Аиффузная Аилатация, заполнение экссудатом и слущенными эпителиальными клетками) в сочетании с вовлечением микрососудов мегких (поражение эндотелия и множественные тромбы) [73]. Пациенты вынужденно переводятся на ИВ $\Lambda$, но и в этом случае успех не гарантирован, так как поражение мегких Аолжно трактоваться не как вирусная пневмония, а как аутоиммунный пневмонит с тотацьным поражением и мегочной ткани («тонущие амьвео$\Lambda ы \gg)$, и сосуаов $[74,75]$.

Наличие коагулопатии, начиная с ранних стаАий развития болезни, позволят считать COVID-19 протромботическим состоянием, требующим активной антикоагулянтной терапии практически у всех больных, как это было принято с первого Аня в практике работы Универ- ситетской кминики МГУ по мечению новой коронавирусной инфекции (наши рекомендации). Мнения специалистов, считать ми коагулопатию при COVID-19 вариантом синарома Аиссеминированного (или септического) внутрисосуаистого свертывания (АВС или СВС), разАемились [76-78]. ОАнако, очевиАно, что именно протромботический статус во многом опредемяет прогноз пациентов с COVID-19 [79, 80]. При этом, сегодня Аоказано аутоиммунное воспаление эндотемия сосудов разных органов с типичными микротромбозами: почек, кишечника, сердца и Ааже простаты. Имеются очевидные свидетельства, что антикоагумянтная терапия достоверно уцучшает прогноз пациентов с COVID-19 [62, 64]. Бомее того, есть Аанные, что чем агрессивнее мечение антикоагулянтами, тем кучше прогноз больных с COVID-19 [81]. Поэтому сегодня обязательная антикоагумянтная терапия явмяется магистральным планом мечения пациентов с COVID-19, уже с ранних стаАий болезни, с увекичением интенсивности по мере прогрессирования тяжести инфекции $[82,83]$. Естественно, при активной антикоагумянтной терапии нельзя забывать о необходимости тщательного контромя за риском кровотечений [84].

Необходимость активной антикоагулянтной терапии у пациентов с COVID-19 на всех стадиях заболевания не вызывает сомнений и доказала свою эффектив-

Рисунок 3. Аутоиммунное воспаление, провоспалительные факторы и возможные точки приложения Аействия потенциальных мекарств при COVID-19

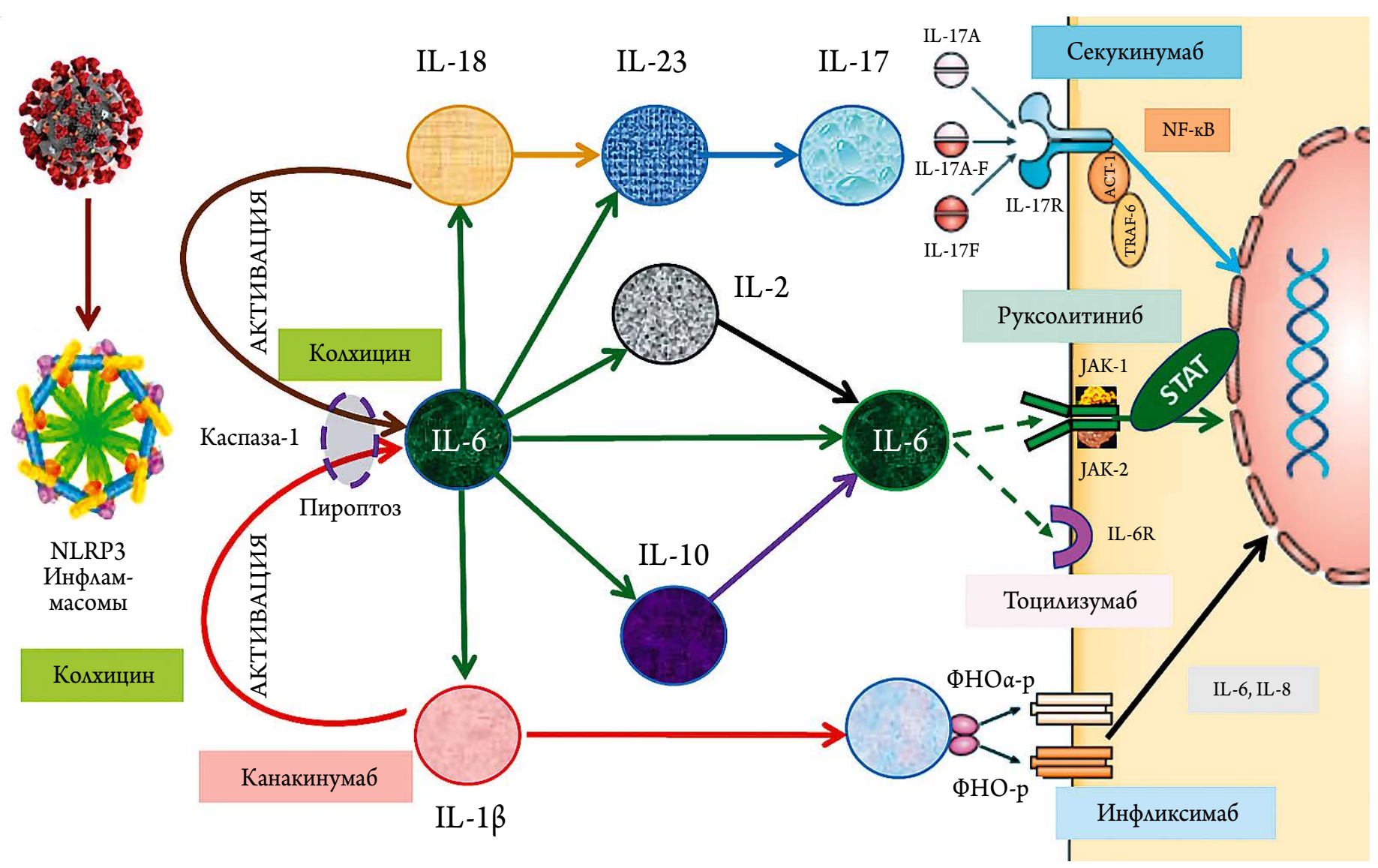


ность $[83,85]$. Но это мишь коррекция послеАствий, связанных с аутоиммунным воспалением. Без влияния на первопричину поражения мегких при COVID-19 невозможно налеяться на успех [86]. Поэтому борьба с системным воспалением Аолжна быть краеугольным камнем мечения COVID-19, особенно тяжелых форм. Учитывая, что активная антикоагукянтная терапия низкомолекулярными гепаринами (НМГ) использовалась у ВСЕХ наших пациентов, предметом исслеАования явился выбор упрежАающей специфической противовоспацительной терапии.

Схема основных факторов, стимулирующих аутоиммунные воспалительные реакции при вирусных инфекциях, преАставмена на рисунке 3 .

Как виАно, при попадании вируса SARS-CoV-2 в бронхи и альвеолы происходит активация инфмаммасом, мультипротеинового комплекса, который через активацию фермента каспаза-1 промотирует процесс пироптоза, то есть программируемой гибели клеток [87]. Это механизм защиты клеток от атакующей их инфекции, что сопровожАается Аесквамацией эпителиальных киеток ацьвеол [88]. В этом случае разрушается мембрана клеток и происходит секреция провоспалительных цитокинов И $\Lambda-1 \beta$ и И $\Lambda-18$ [89]. ОАним из основных послеАствий этого явмяется промоция выработки все большего количества И $\Lambda$-6 в ответ на продолжающуюся вирусемию [90]. ИА-6 считается ключевым стимумятором аутоиммунной защиты, переходящей в воспаление, и при его избыточной секреции «срыву» в цитокиновый шторм, усугубляющий течение коронавирусной пневмонии [91]. Процесс при COVID-19 вкмючает в себя активацию достаточного числа разАичных хемокинов и цитокинов, способных поААерживать состояние аутоиммунного воспаления и повышенного тромбообразования, в том числе ИА-17 [92] и фактор некроза опухоли амьфа (ФНОа) [93].

ИсхоАя из этой концепции, можно наметить разАичные точки приложения Аействия мекарственных препаратов, способных прерывать процесс неукротимого воспамения и тромбообразования, что теоретически может помочь в мечении COVID-19 (рис.3). В попытке снижения выработки ИА-6 возможно испомьзование специфических антител к интерлейкину И $\Lambda$-1 $\beta$ [94]. Кстати, препарат с таким Аействием канакинумаб достоверно снижац риск смерти у пациентов после перенесенного инфаркта миокарда за счет снижения выраженности аутоиммунного воспаления [95]. Наиболее попукярной илеей борьбы с цитокиновым штормом оказалось использование антител к рецепторам ИА-6 (тоцимизумаб и сарикумаб), которые с самого начала эпидемии рассматривались, но, к сожамению, не Аля ранней терапии, а Аля больных, уже находящихся на ИВА в качестве «послеАней соломинки» в борьбе с цитокиновым штормом [96]. Это мы обсужАали выше. Альтернативной возможностью виАится испомьзование бцокаторов янус-киназ (JAK-1, JAK-2), через которые передается эффект основных цитокинов, в том числе И $\Lambda-6$ на клетки, прежде всего руксолитиниба, с которым уже проведены небольшие, но перспективные исследования у больных с COVID-19 [97]. Важную роль в реацизации аутоиммунного ответа может играть и ИА-17, при чрезмерной активации стимулирующий провоспалительное состояние и наклонность к тромбозам [98-100]. Интересное наблюдение пришло с севера Италии, где у пациентов с псориазом, находившихся на плановом мечении секукинумабом, имемо место крайне мягкое течение COVID-19 [101]. Исходя из этого, применение моноклонамьных антител, блокирующих ИА-17, например, секукинумаба в мечении COVID-19 выгмяАит также многообещающе $[92,102]$. Конечно, применение биологических противоиммунных препаратов в мечении вирусных инфекций, вкмючая COVID - 19, преАставляется поисковым направлением, так как преАсказать и Ааже обосновать эффективность тех или иных антицитокиновых препаратов сегодня уверенно невозможно [103, 104]. Кроме этого, агрессивная антицитокиновая терапия чревата развитием суперинфекций, которые могут оказаться более опасными Аля судьбы пациентов с COVID-19, чем польза от самой противовоспалительной терапии [105].

Бомьшой интерес вызывает использование хорошо известного препарата, в настоящее время применяющегося в качестве средства выбора в мечении обострений поАагры, - комхицина [106]. Внимание к комхицину в последние годы не ослабевает, его эффективность была продемонстрирована у больных с перенесенным острым инфарктом миокарда [107]. Основные противовоспамительные эффекты колхицина связаны с блокадой инфламмасом, уменьшением пироптоза и снижением активации цитокинов [108]. Кроме того, колхицин, связываясь с внутриклеточным белком тубулином, образующим микротрубочки, может нарушать проникновение вирусов в яАра клетки и их последующую репликацию, снижая вирусную нагрузку [109]. И первое завершенное рандомизированное исследование по лечению больных COVID-19 с комхицином, GRECCO-19, укрепило надежАы на него, как на потенциальное мекарство Аля мечения этой инфекции [110]. Применение комхицина сокращамо срок Ао Аостижения нормализации клинического состояния, но не было зафиксировано значимого снижения С-РБ как маркера воспаления. На сегодня колхицин явцяется одним из наиболее изучаемых препаратов в мечении COVID-19 (рандомизированные проспективные протоколы COLCORONA [111], 6000 бомьных, и COLCOVID [112], 2500 бомьных). 
Рисунок 4. КОАхицин прОтив Руксолитиниба И секукинумаба в оТкрытом проспективном рандомизируемом исслеАовании у пациентов с COVID-19 (КОАОРИТ)

\begin{tabular}{|c|c|c|c|}
\hline \multicolumn{4}{|c|}{ 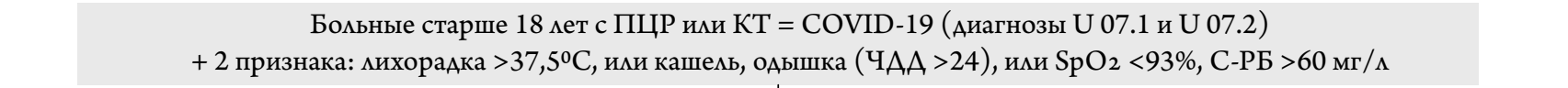 } \\
\hline \multicolumn{4}{|c|}{ 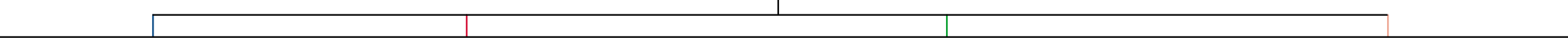 } \\
\hline $\begin{array}{c}\text { Обычная } \\
\text { терапия } \\
\text { (контромь) }\end{array}$ & $\begin{array}{l}\text { Обычная терапия } \\
\quad+\text { Комхицин } \\
1 \text { мг }->0,5 \text { мг х } 2 \text { p/c }\end{array}$ & $\begin{array}{c}\text { Обычная терапия } \\
+ \text { Руксолинитиб (Ажакави), } \\
5 \text { мг }->2 \text { p/с } 14 \text { Аней }\end{array}$ & $\begin{array}{c}\text { Обычная терапия } \\
\text { + Секукинумаб } \\
\text { (Козэнтикс), } 300 \text { мг подкожно }\end{array}$ \\
\hline \multicolumn{4}{|c|}{14 Аней мечения ПАЮС к терапии АКГ и \pm антибиотики + Бромгексин 8 мг х 4 p/A + спиронолактон 50 мг/сут } \\
\hline \multicolumn{4}{|c|}{ Первичная конечная точка = Аинамика баммов по шкаме ШОКС-COVID (Ю. В. Мареев) } \\
\hline \multicolumn{4}{|c|}{ 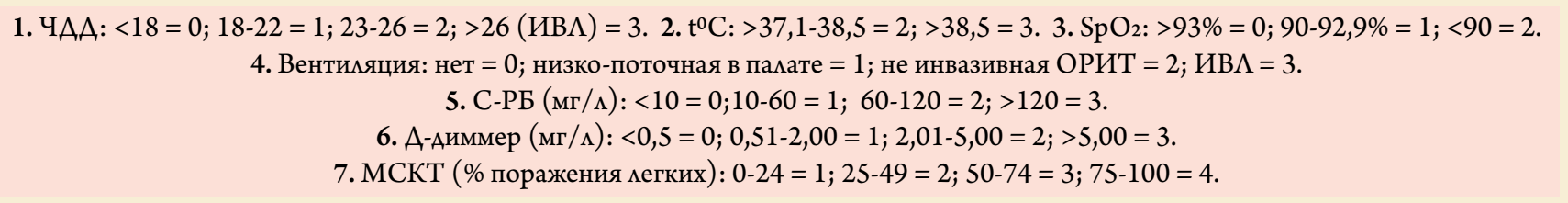 } \\
\hline \multicolumn{4}{|c|}{$\begin{array}{l}\text { Вторичные конечные точки: Аинамика С-РБ; Аинамика D-Аимера; на } 14 \text { и } 45 \text { Ани мечения. } \\
\text { Степень поражения мегких на МСКТ; КЖ по ВАШ и по шкаме EQ-5D на } 14 \text { и } 45 \text { Ани мечения. } \\
\text { инический статус и комбинация смерти + потребности вентимяции мегких на } 14 \text { и } 45 \text { Ани мечения. }\end{array}$} \\
\hline
\end{tabular}

ПЦР - полимеразная цепная реакция; КТ - компьютерная томография; ОРИТ - отделение реанимации и интенсивной терапии; ШОКС-COVID - Шкала оценки клинического состояния при коронавирусной инфекции 19 (COVID-19); ЧАА - частота Аыхательных Авижений; ИВ МСКТ - мультиспиральная компьютерная томография; ВАШ - визуальная аналоговая шкала.

Мы также выполнили проспективное рандомизированное исследование по ранней упрежАающей противовоспалительной терапии больных с COVID-19, получившее название КОАОРИТ [113], схема которого преАставлена на рисунке 4.

Как видно, пациенты с доказанной COVID-19 и еще Авумя признаками: кихорадкой $>37,5^{\circ} \mathrm{C}$ и сохраняющимся кашлем, оАышкой с частотой Аыхательных Авижений (ЧАА $>24$ в мин или сатурацией кисморода $<93 \%$ и уровнем С-РБ >60 мг/ рандомизировались в 4 группы: контроль (без специфической противовоспалительной терапии); мечение колхицином 1 мг в первый день и затем 0,5 мг/сут.; мечение руксолитинибом (Ажакави ${ }^{\circledR}$ ) по 5 мг $\times 2$ р./ сут.; мечение секукинумабом (Козэнтикс $\left.{ }^{\circledR}\right)$ 300 мг подкожно однократно). Первичная конечная точка включала количество бамлов по оригинальной шкале ШОКС-КОВИА, которую мы использовали ранее в исследовании с ГКС ПУТНИК [55]. Вторичными точками исследования были: Аинамика кминического состояния, компоненты первичной точки, прежде всего, С-РБ и $\mathrm{D}$-Аимер, качество жизни по визуально аналоговой шкаме и валидированному Европейскому опроснику EQ-5D, а также Алительность госпитализаций, потребность в механической вентимяции мегких и прогноз к 14-му и 45-му Аням мечения.

В качестве базовой терапии у всех больных использовались высокие дозы антикоагумянтов (НМГ), сочетание бромгексина и спиронолактона, и необходимые по ситуа- ции антибиотики. В ближайшее время мы подведем итоги этой работы, а в настоящей статье преАставим Аюбопытные реальные клинические наблюдения, позволяющие убедиться в целесообразности исслеАований по упрежАающей противовоспалительной терапии.

Больная И., 53 года, с положительным тестом на SARS$\mathrm{CoV}-2$ (полимеразная цепная реакция (ПЦР)), мечилась от Авусторонней коронавирусной пневмонии в московской клинике в течение 21 Аня (без специфической противовоспалительной терапии) и была выписана с клиническим улучшением, нормальной температурой тела, минимальной выраженностью одышки, поражением мегких 1-й степени (по МСКТ, Рекомендации МЗ РФ), нормальными

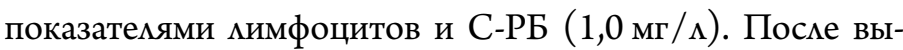
писки через 3 Аня вновь повысилась температура тела, наросла одышка, был рекомендован прием мопинавира/ритонавира, азитромицина, парацетамома и мизатов бактерий. Состояние не укучшалось, и 6 мая (на 4-е сутки после появмения симптомов) госпитализирована в Университетскую КАинику МГУ имени М.В. Аомоносова. ПЦР тест на наличие PHK вируса SARS-CoV-2 отрицательный.

При поступлении субфебрильная лихорадка $37,9^{\circ} \mathrm{C}$; умеренная одышка (ЧАА 18 в 1 мин); сатурация кисморода 98\%; мимфоциты на нижней границе нормы $1,01 \times 10^{9} / \Lambda ; и Н / \Lambda 3,8 ;$ скорость осеАания эритроцитов (СОЭ) 21 мм /час; ИА-6 11,9 пг /ми; С-РБ 54,8 мг/ и D-димер 0,72 мкг/ми. На МСКТ (рис. 5) небольшое поражение мегочной ткани, преимущественно слева, 
объемом 6,1\%, но с участками консолидации. Это было расценено как разрешение Алительного воспалительного процесса. Несмотря на умеренное повышение провоспалительных факторов (ИА-6 и С-РБ), относительно спокойная клиническая картина и минимальное поражение мегких при отрицательном ПЦР тесте на COVID-19 не заставили нас сразу начать противовоспалительное мечение. Была назначена антикоагулянтная терапия (эноксапарин 0,6 мк $\times 1$ р./сут. подкожно), антибиотики (моксифмоксацин 400 мг / сут.) и сочетание бромгексина 8 мг $\times 4$ р. / сут. и спиронолактона 50 мг/сут. Прогрессировано заболевание стремительно - через 2 суток 8.05 сохранялась субфебримьная температура $37,8^{\circ} \mathrm{C}$, усиликась оАышка до 22 в 1 минуту, снизикась сатурация кислорода Ао 96\% при нахожАении пациентки в «прон» позиции, повысилась СОЭ Ао 56 мм/час, количество лимфоцитов и иН $/ \Lambda$ изменились мало. ОАнако резко

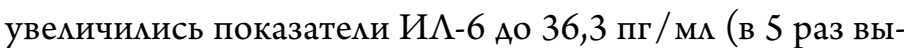
ше нормы) и С-РБ до 214,8 мг / Ал (в 43 раза выше нормы). D-Аимер также увеличился Ао 1,16 мкг / мл. За Авое суток объем поражения мегких увеличился до 44\% (причем в обоих мегких, преимущественно в виде вновь появившихся матовых стекол). Этот пример показывает, как мегко ошибиться и недооценить тяжесть состояния больных с COVID-19. У этой пациентки регистрирова ся второй тип реакции на инфекцию в виде синдрома повышенного высвобождения цитокинов (зеленая киния рис. 2). С этого момента быма начата терапия колхи- цином 1 мг в первый день и затем 0,5 мг / сут. и увеличена доза эноксапарина до 0,6 мл 2 р./ сут. подкожно. Постепенно состояние стало нормализовываться, и через 2 недели было достигнуто очевидное укучшение: температура тела $36,5^{\circ} \mathrm{C}$; сатурация кислорода $98 \%$; ЧАА

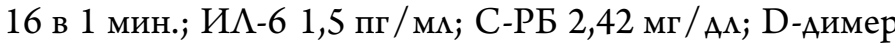
0,2 мкг/ми, и объем поражения мегких снизился с $44 \%$ Ао 7\%, в виде матовых стекол. Хочется отметить, что при втором типе реакции иммунной системы очень быстро происходит переход воспалительной реакции в массивное поражение мегочной ткани. Своевременно начатая специфическая противовоспалительная терапия позвомяет также относительно быстро (в течение 1-2 недель ) побороть коронавирусную пневмонию.

Больной С., 69 мет, с индексом массы тела 30,7 кг/м², с подтвержденной ПЦР COVID-19 и Авусторонней помисегментарной пневмонией поступил в клинику на 12 -й день болезни с сохраняющейся михорадкой (максимум до $39^{\circ} \mathrm{C}$, при поступлении $37,5^{\circ} \mathrm{C}$ ), одышкой с ЧАА 20 в 1 мин, сохраняющимся сухим кашлем и снижением сатурации кислорода до 96\%. Сопутствующие заболевания: гипертоническая болезнь 2-й ст., атероскмероз аорты, брахиоцефальных артерий, дислипидемия. Аля контроля АА и мипидов продолжен прием мозартана 50 мг 2 р./сут., бисопролола 2,5 мг 1 р./сут., розувастатина 10 мг 1 p./сут.

В анализах крови выраженная мимфопения $0,5 \times 10^{9} / \Lambda$;

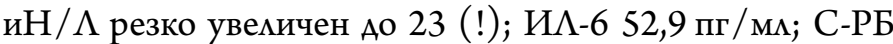

Рисунок 5. МСКТ мегких больной И, 53 года, с COVID-19 и Авусторонней пневмонией (объяснение в тексте)
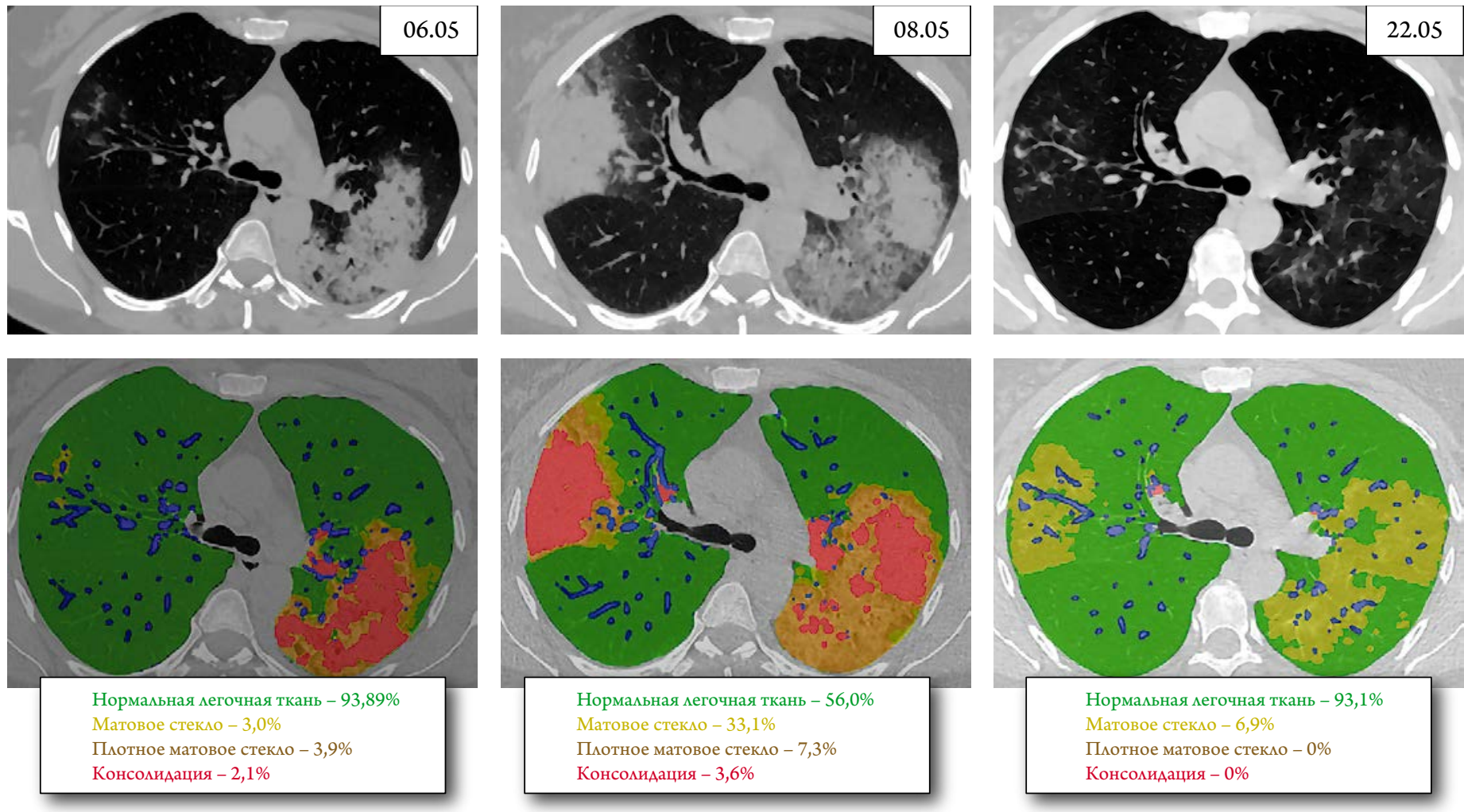
Рисунок 6. МСКТ мегких больного И, 69 мет, с COVID-19 и Авусторонней пневмонией (объяснение в тексте)
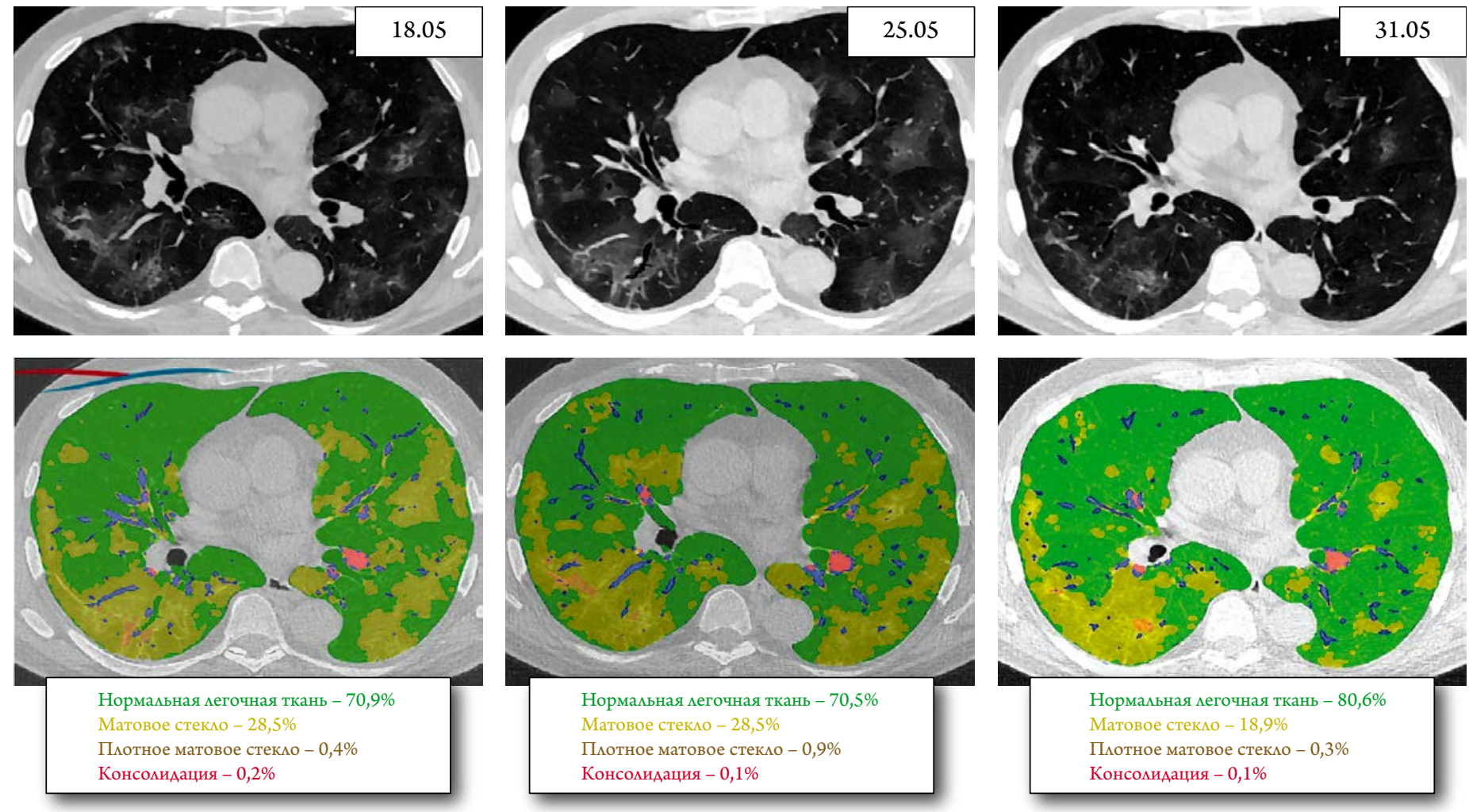

159,5 мг/Ац; D-Аимер 0,84 мкг/мл. На МСКТ авустороннее поражение мегких, общим объемом $30 \%$, преимущественно в виде матовых стекол (рис. 6).

Состояние было расценено как тяжелое аутоиммунное воспаление, требующее экстренного воздействия. В Аанном скучае имеет место третий тип реакции иммунной системы на вирусную инфекцию в виде замедленного синАрома высвобождения цитокинов (красная Аиния на рисунке 2) и Алительного упорного течения вирусной инфекции, трудно подАающейся терапии.

Начата терапия бромгексином 8 мг 4 р./сут., спироно-

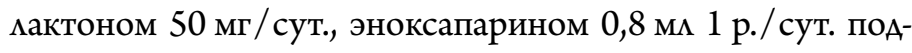
кожно, цефтриаксоном по 1000 мг 2 р./сут. После получения информированного согласия больному в первый же Аень пребывания в стационаре был назначен руксолитиниб (Ажакави $\left.{ }^{\circledR}\right)$ в дозе 5 мг 2 р./ сут. (малые дозы использованы во избежание реакции ослабления кроветворения).

КАиническое состояние Аостаточно быстро укучшамось, через Авое суток нормализовалась температура те$\Lambda$ а, ЧАА снизилась Ао 18 в 1 минуту; сатурация кислороАа возросла до 98\%; С-РБ снизился до 98,3 мг / Ал на вто-

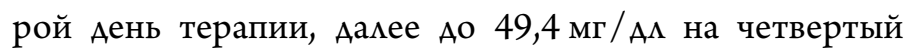
Аень мечения, и к концу первой недели - Ао 6,76 мг/Ал. В это же время возросло Ао нижней границы нормы число мимфоцитов $1,1 \times 10^{9} / \Lambda$ и резко снизился иН $/ \Lambda$ Ао 2,7 и D-Аимер до 0,55 мкг/мм. Несмотря на это, площадь поражения мегочной ткани практически не уменьшилась (рис. 6).
Еще через 6 Аней состояние нормализовалось: температура тела $35,5^{\circ} \mathrm{C}$, одышки (ЧАА 16 в 1 минуту) и кашмя нет; сатурация кислорода 99\%; увеличимось до нормы число лимфоцитов $1,63 \times 10^{9} / \Lambda$ и иН $/ \Lambda=2,0$. На фо-

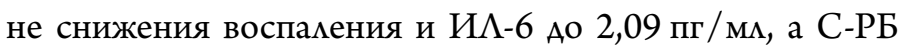
Ао 1,08 мг / Ал нормализовался и А-Аимер 0,25 мкг / мл. Но на МСКТ все еще сохранялось поражение, преимущественно в правом кегком, общим объемом $20 \%$, в виде матовых стекол. Это типично Амя третьего типа реакции иммунной системы на вирусную инфекцию, когАа развитие пневмонии происходит постепенно, достигая максимума ко 2-3-й недеме. В этих скучаях даже активная, эффективная и вовремя начатая противовоспалительная терапия, например, руксолитинибом (Ажакави $\left.{ }^{\circledR}\right)$, не позволяет быстро устранить мегочный фиброз. СегоАня имеются Аанные, что не все симптомы болезни проходят в острый периоА инфекции и нереАко встречаются и через месяц после госпитального мечения [114].

Больной К., 31 гоА, с ПЦР-поАтвержАенной вирусной пневмонией и сопутствующей хронической обструктивной бомезнью мегких и бронхиальной астмой, поступим на 8-й Аень болезни с жалобами на михораАку (при поступлении $37,6^{\circ} \mathrm{C}$ ), оАышку (ЧАА 20 в 1 мин), чувство заложенности в груАи вне связи с физической нагрузкой, гомовную боль, одышку преимущественно в ночное время, малопродуктивный кашель со скуАной светлой мокротой с коричневатыми включениями, потерю вкуса и обоняния, тошноту, слабость. В связи с бронхиамьной аст- 
Рисунок 7. МСКТ мегких больного К., 31 гоА, с COVID-19, Авусторонней пневмонией и бронхиальной астмой (объяснение в тексте)
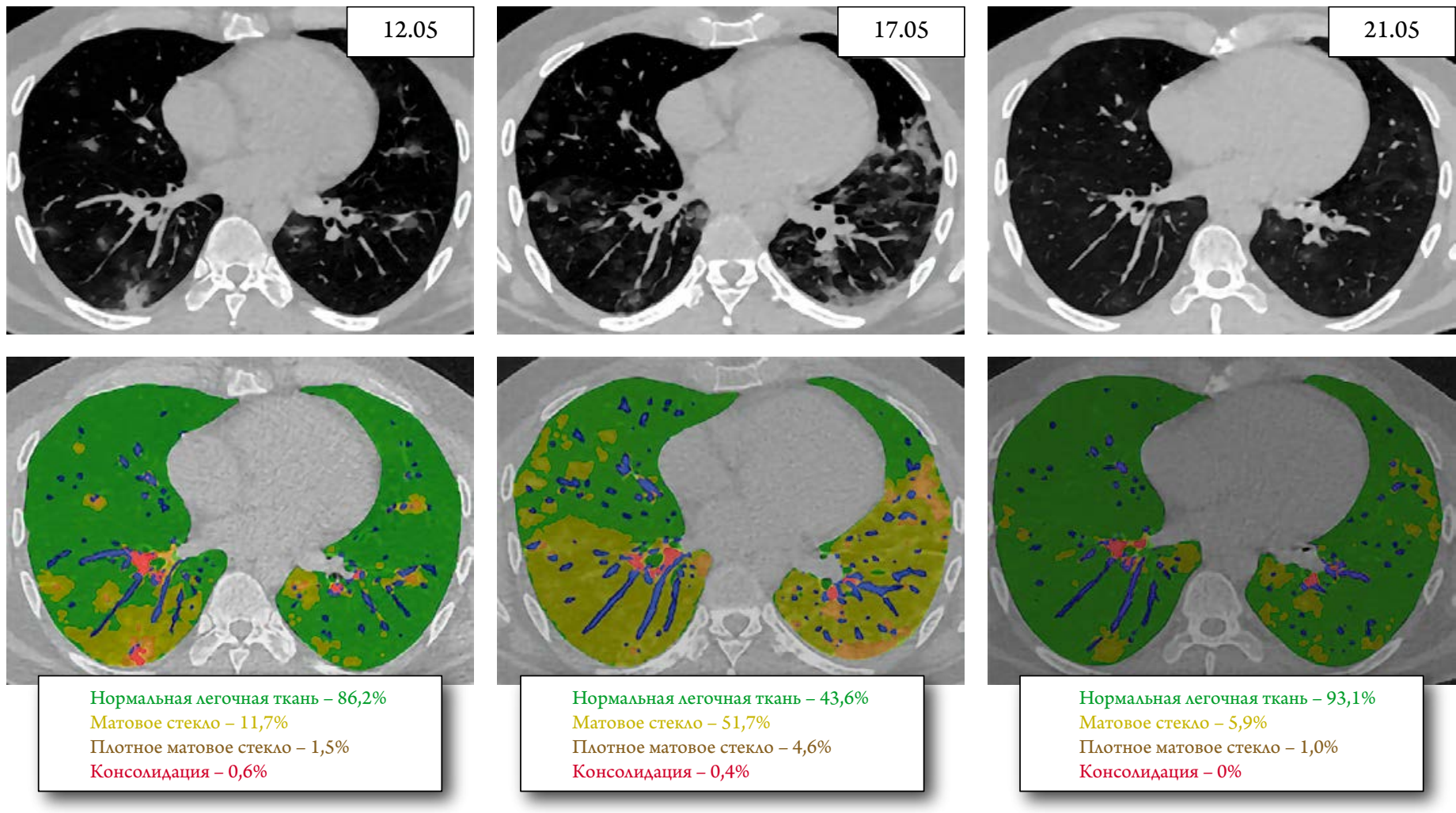

мой с детства использует беклометазон 2 вдоха 2 р./сут. и ситуационно ипратропия бромиА + фенотерол. В связи с подозрением на COVID-19 амбулаторно принимах в течение 7 Аней имиАазолилэтанамиА пентандиовой кислоты, парацетамол; с четвертого Аня болезни был назначен гидроксихлорохин 400 мг / сут. (отменен в связи с развившейся крапивницей) и азитромицин без очевидного поможительного эффекта.

При поступлении существенное снижение сатурации кислорода до 93\% связывалось в большей степени с бронхиальной астмой, чем с вирусной пневмонией. 12.05.2020 на МСКТ (рис. 7) зона поражения составмяла

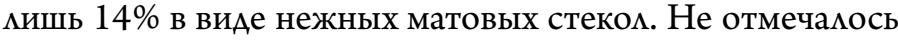
мимфопении $\left(2,03 \times 10^{9} / \Lambda\right)$ и повышения иН/ $\Lambda$, уровня

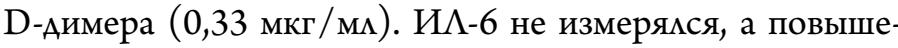
ние С-РБ до 69,4 мг/ Ал вкупе с умеренным повышением

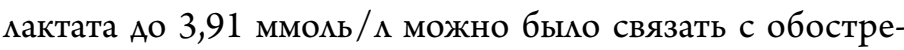
нием бронхиальной астмы. Кроме того, обращала на себя внимание тромбоцитопения $\left(135 \times 10^{9} / \Lambda\right)$. К терапии Аобавмены бромгексин 8 мг 4 р/сут, Авойная антибиотикотерапия цефтриаксон 1000 мг 2 р/сут. и амоксицимлин + клавулановая кислота по 1000 мг внутривенно 3 р/сут., и антикоагулянт эноксапарин 0,4 ми 1 р./ сут. подкожно.

Несмотря на такую терапию, состояние пациента существенно не улучшилось, хотя прошли кашель, заложенность в груАной клетке, но сохранялись субфебримитет и одышка при сатурации кислорода 93-94\%. Через 5 Аней (13-й Аень болезни) отмечено повышение

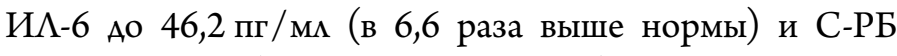
Ао 201,1 мг/ ал (в 40 раз выше нормы), при нормальном уровне D-Аимера 0,17 мкг/ми, что позволило преАположить развитие промежуточного (с переходом от второго к третьему) типа аутоиммуннного ответа с синдромом высвобождения цитокинов (рис. 2). У больного отмечено очень быстрое нарастание поражения мегочной ткани по МСКТ с 14 до 57\% за пять суток, в виде распространенных очагов матовых стеком в обоих мегких. После получения информированного согласия была проведена подкожная инъекция моноклонального антитела к ИА-17 секукинумаба (Козэнтикс ${ }^{\circledR}$ ) в дозе 300 мг.

Эффект проявился уже к третьему Аню кечения в виАе нормахизации температуры тела, возврате обоняния

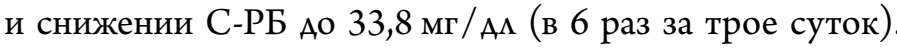
К 5 Аню мечения: температура тела $36,5^{\circ} \mathrm{C}$; ЧАА 16 в 1 минуту; сатурация кислорода 99\%; мимфоциты 2,41 × $10^{9} / \Lambda$; иН/ $\Lambda$ 1,1; количество тромбоцитов увеличилось

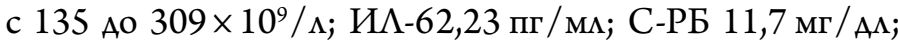
D-димер 0,53 мкг/ми. На MCKT быстрое уменьшение зоны поражения мегких с 56 Ао 6\% (также за пять суток) ЕАинственно, можно заметить, что доза НМГ быма невысокой из-за имевшейся у пациента тромбоцитопении. С этим, частично, можно связать пограничную векичину D-димера к концу терапии. Поэтому при выписке быи рекомендован прием пероральных антикоагулянтов (ривароксабан 10 мг /сут.). В остальном - снова яркий пример быстрого успеха противовоспахительной терапии секу- 
кинумабом у молодого пациента все-таки со вторым типом аутоиммунного ответа, несмотря на сопутствующую бронхиальную астму. Задержка противовоспалительного мечения не сыграма решающей роли, благодаря молоАости пациента и «тренированной» иммунной системе.

Бомьной А., 80 мет, поступим в клинику на 6-й Аень бомезни с поАтвержАенным ПЦР COVID-19 и Авусторонней коронавирусной пневмонией. Сопутствующие заболевания: сахарный Аиабет 2 типа (медикаментозно компенсирован), гипертоническая болезнь 2-й ст., хронический гломерулонефрит (Аатентная форма), Авусторонние кисты почек, хроническая болезнь почек стаАия 5 , послеоперационный гипотиреоз (меАикаментозно компенсирован), подагра, Аоброкачественная гиперплазия преАстательной железы, спондилоартроз. В качестве терапии сопутствующих заболеваний получал: глимепириА 1 мг/сут. плюс алоглиптин 25 мг/сут. Аля контро-

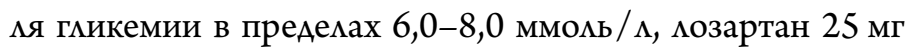
2 р./сут., фуросемиА (периодически поА контролем Аиуреза) и небиволол 7,5 мг / сут. Аля контроля АА на уровне 140/80 мм рт. ст.; аторвастатин 40 мг 1 р./ сут. Аля контроля холестерина.

Заболевание началось остро с повышения температуры тела до $39^{\circ} \mathrm{C}$, одышки, кашия, болей в горле, выраженной слабости, полной потери обоняния, Аиареи. Амбулаторно проводилось мечение цефазолином, бромгексином, парацетамолом. Несмотря на проводимую терапию, в тече- ние нескольких послеАних Аней отмечает ухудшение состояния, нарастание одышки, астении. По Аанным МСКТ (амбулаторно): Авусторонняя полисегментарная пневмония, высокая вероятность коронавирусной пневмонии 1-й стаАии (то есть пиощадь поражения мегких менее 25\%).

При поступлении в МНОЦ МГУ температура тема $37,9^{\circ} \mathrm{C}$; выраженная одышка (ЧАА 22 в 1 минуту); частота сердечных сокращений 100 уА/мин, АА 140/70 мм рт. ст. Сатурация кислорода 92\%. Больной не в состоянии находиться в прон-позиции в связи с обострением спондилоартроза. На МСКТ умеренное поражение мегочной ткани 28,8\%, больше слева и $11 \%$ уже пиотные матовые стекла, то есть участки теряющей возАушность мегочной паренхимы (рис. 8). Это уже соответствует 2-й стадии поражения (по классификации МЗ РФ). В анализах крови мейкоцитоз $12,3 \times 10^{9} / \Lambda$; относительная мимфопения $1,11 \times 10^{9} / \Lambda$ и выраженный нейтрофимез $10,69 \times 10^{9} / \Lambda ;$ иН/ $\Lambda$ повышен до 9,6; СОЭ 38 мм/час. Отмечается повышение всех провоспалительных факто-

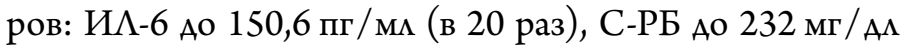

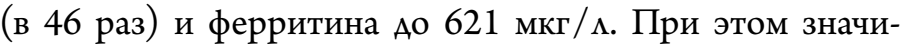
тельно повышен и D-Аимер до 2,62 мкг/ми (более, чем в 5 раз). Ситуация осложнялась и проявлениями почечной недостаточности - уровень креатинина быи повышен Ао 344 мкмоль/ и и скорость кмубочковой фильтрации (СКФ) снижена до 14 мл/мин/1,73 м² (по формуме CKD-EPI). Уровень глюкозы незначительно повышен

Рисунок 8. МСКТ мегких больного А., 80 мет, с COVID-19, Авусторонней пневмонией и сахарным Аиабетом 2 типа, ХБП 5 стаАии, артериальной гипертонией, подагрой (объяснение в тексте)
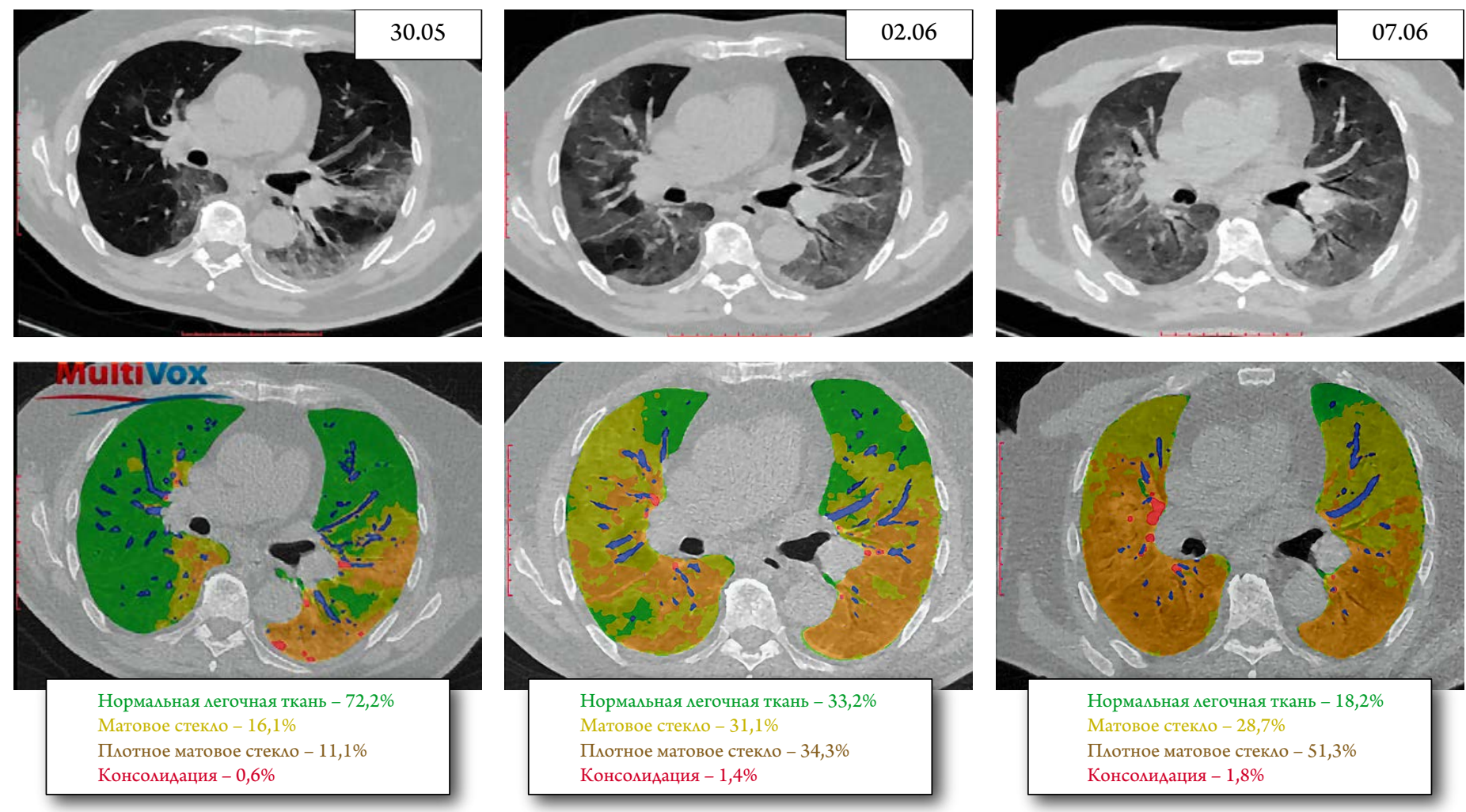
Ао 6,8 ммоль / , но была опасность развития мактоацидоза (цактат 7,1 ммоль / $)$.

Быма начата симптоматическая терапия бромгексином по 8 мг 4 р./сут. плюс ацетилцистеин, а также кетопрофеном внутривенно при болях, тизанидином гидрохморидом 2 мг / сут. и омепразолом. В качестве антибактериальной терапии был назначен мевофмоксацин 500 мг внутривенно 1 р./сут. Антикоагулянтное мечение вкмючимо применение эноксапарина в Аозе 0,6 мл 2 р./сут. подкожно. Состояние было расценено как выраженное аутоиммунное воспаление с возможным прогрессированием в цитокиновый шторм (сиреневая линия на рис. 2). После покучения информированного согласия пациента немедленно была начата терапия секукинумабом $\left(\right.$ Козэнтикс $\left.{ }^{\circledR}\right) 300$ мг подкожно и дексаметазоном по 8 мг 2 р./сут. внутрь.

В течение последующих 3 суток температура тема не превышала $37,2^{\circ} \mathrm{C}$; одышка и слабость немного уменьшились, но сатурация кислорода оставалась очень низкой - 86\% при дыхании атмосферным воздухом и 94\% при дыхании кислородом (V 5 к/мин). Показатели креатинина практически не изменились, но отмечалось повышение уровня глюкозы до 10,3 ммоль/ $\Lambda$, несмотря на продолжающуюся гипогликемическую терапию. Сохранялся мейкоцитоз $12,7 \times 10^{9} / \Lambda$; прогрессировала Аимфопения до $0,41 \times 10^{9} / \Lambda$ и иН $/ \Lambda$ возрос до 31 ,

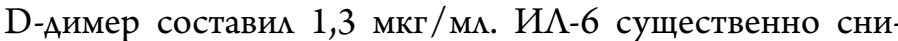
зился до 23,5 пг/мл, С-РБ постепенно снижался по Аням: $232 \mathrm{MГ} / \mathrm{A \Lambda} ; 231 \mathrm{мГ/А \Lambda ;} 121 \mathrm{MГ} / А \Lambda ; 110 \mathrm{MГ/А \Lambda .} \mathrm{Несмо-}$ тря на это, на МСКТ от 02.06.2020, на 11 Аень болезни (рис. 8) отмечено значительное нарастание поражения мегочной паренхимы, особенно в нижних Аомях Ао 66,8\% и зон плотного матового стекла со сниженной возАушностью до 34,3\%, что уже соответствовало 3-й стадии поражения (рекомендации МЗ РФ).

Консилиум Университетской кминики МГУ имени М. В. Аомоносова расценил состояние больного как прогрессирующее аутоиммунное воспаление с развитием полноценного цитокинового шторма, не поААающегося мечению антителами к И Бымо принято решение об изменении антибиотикотерапии (с переводом пациента на цефаперазон+сумьбактам 1000 мг 2 р./сут.) и проведении экстренной пульстерапии высокими дозами ГКС по схеме метимпреднизомон 500 мг - 500 мг - 250 мг - 125 мг внутривенно в сочетании с колхицином в дозе 1 мг в первый день, затем по 0,5 мг / сут. Кроме этого, учитывая риск ацидоза, к терапии добавлен ацетазоламиА 250 мг 2 р./ сут. После консультации эндокринолога было принято решение о переводе пациента на инсулин. Проводимое цечение позволимо в течение 5 Аней (к 16-му Аню болезни) добиться

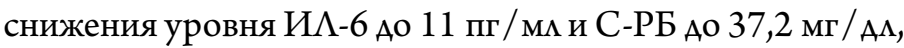

но состояние ухудшалось, усиливалась одышка и заложенность в груди, сатурация кислорода оставалась низкой (85-88\% при дыхании атмосферным воздухом и 9294\% при Аыхании кислородом (V 10 «/мин)). Прогрессировала слабость, астения, появилось чувство депрессии и тревоги, в связи с чем был назначен гиАроксизин 25 мг на ночь. Сохранялась упорная мимфопения $0,5 \times 10^{9} / \Lambda$, увеличился мейкоцитоз Ао $20,2 \times 10^{9} / \Lambda$ и резко возрос иН $/ \Lambda$ Ао 38,4. Сохранялась гипергликемия 10,9 ммоль / и умеренное повышение кактата Ао 4,24 ммоль/ сокий уровень креатинина 382 мкмоль $/ \Lambda$ и критически низкая расчетная СКФ $12 \mathrm{м \Lambda} /$ мин/1,73 м² (по формуме CKD-EPI). Относительная плотность мочи была снижена до 1005, имела место амьбуминурия 0,5 г/ козурия (+), кетоны $(+)$, гематурия 65,9 кл/мкА и опреАелялось повышенное содержание Арожжей в моче 58,8 кл/мкм. Оставался повышенным и уровень D-димера Ао 1,78 мкг/ми. На контрольной МСКТ (рис. 8) фиксировалось Аальнейшее прогрессирование поражения мегочной паренхимы более $80 \%$ с обеих сторон, и практически не вентилируемые зоны в виде плотного матового стекла занимали более половины мегочной паренхимы (4-я стадия по классификации МЗ РФ).

Быка вновь изменена терапия антибиотиками и назначен меропенем по 2-3 г/сут. в зависимости от величины СКФ и метронидазол 500 мг 2 р./сут. На следующий день нарастало затруднение дыхания, увемичимось тахипноэ до 28 в минуту с участием в акте Аыхания вспомогательной мускулатуры и снижением сатурации кислорода Ао $88 \%$ на фоне дыхания увлажненным кислородом. Больной быи переведен в ОРИТ, гАе проводилась неинвазивная вентимяция мегких со скоростью $10 \Lambda$ /мин через маску, осуществмялась коррекция водно-эмектролитных нарушений, Амя стабилизации гемодинамики использованы малые дозы нораАреналина и симптоматическая терапия. Продолжалась интенсивная Авойная противовоспалительная (Аексаметазон и колхицин) и антикоагулянтная (эноксапарин) терапия. Состояние больного оставалось тяжелым, в связи с закрытием клиники как центра по мечению COVID-19, пациент быи переведен в реанимационное отделение городской больницы (17-й Аень болезни), где на следующий день была констатирована смерть (18-й день болезни).

Последний пример демонстрирует классическое течение цитокинового шторма и прогрессирующего поражения мегких при COVID-19, когАа никакие усилия не позволяют «переломить» ситуацию и мюбая, в том чисме комбинированная антикоагулянтная и противовоспалительная, терапия оказывается неэффективной. Конечно, в Аанном случае усугубцяющими факторами были возраст и множественные сопутствующие заболевания, но и в этом скучае кишь упрежАающая терапия 
ATTEHTO

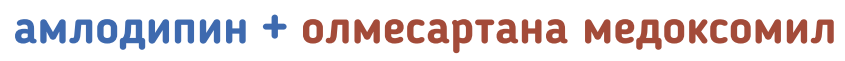

\section{Фиксированная комбинация:}

Эффективное снижение АД',2

$\oslash$ Кардио- и ангиопротективный эффект $\overbrace{}^{\circ}$
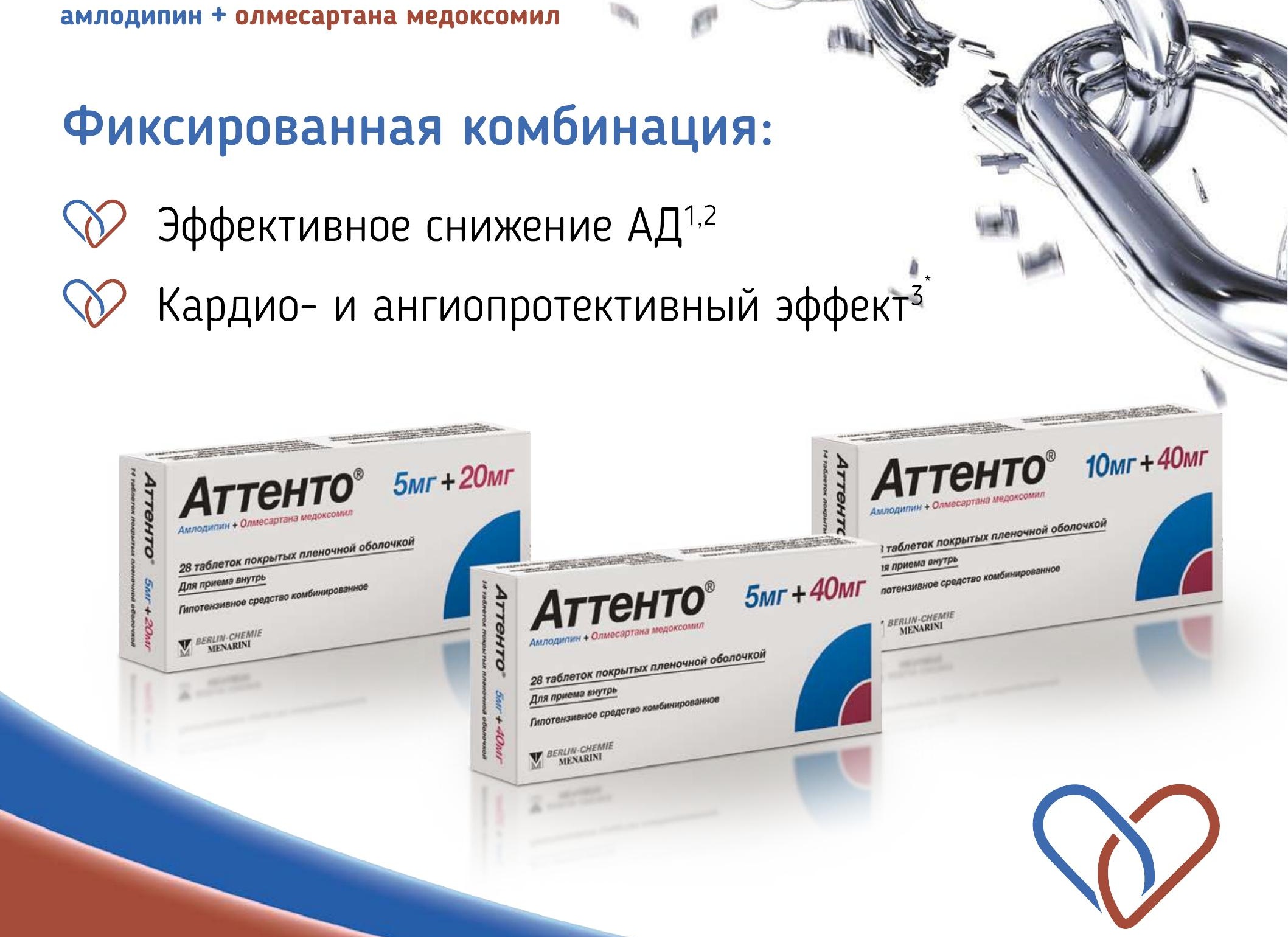

Сокращенная информация по применению лекарственного препарата Аттенто ${ }^{\circledR}$

Показания к применению: Эссенциальная гипертензия (при неэффективности монотерапии олмесартана медоксомилом или амлодипином).

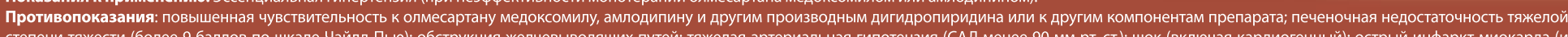

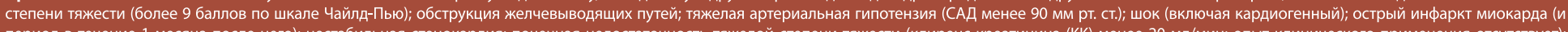

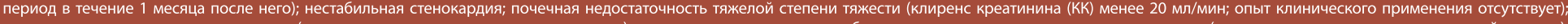

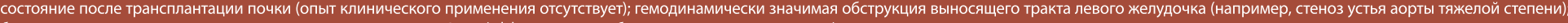

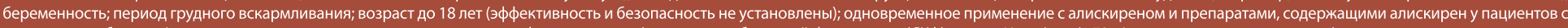

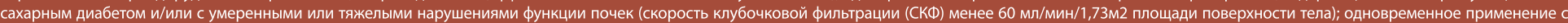
ингибиторами АПФ у пациентов с диабетической нефропатией.

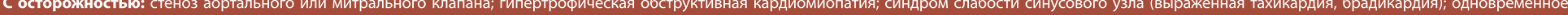

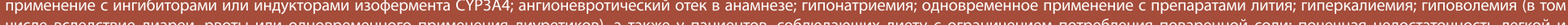

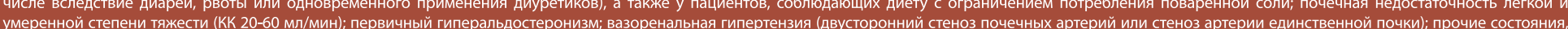

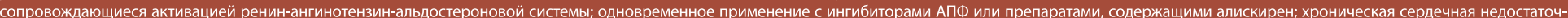

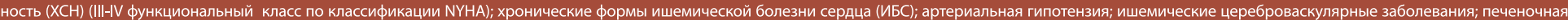
недостаточность легкой и умеренной степени тяжести (менее 9 баллов по шкале Чайлд-Пью); пожилой возраст (старше 65 лет); применение у пациентов негроидной расы.

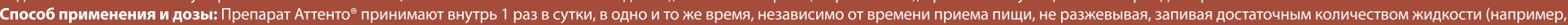

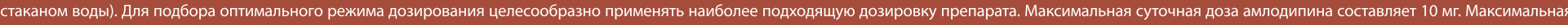
суточная доза олмесартана медоксомила составляет 40 мг.

Побочное действие: Наиболее частыми нежелательными реакциями при применении препарата Аттенто являются периферические отеки (11,3\%), 
могма оставить шансы на успех и измечение пациента от COVID-19. К моменту начала активного противовоспалительного мечения (7-й день болезни) уже имело место кратное увеличение уровней ИА-6, С-РБ и феррити-

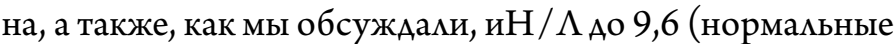
значения до 3). Аахее, несмотря на агрессивную противовоспалительную и антикоагулянтную терапию, пневмония стремительно прогрессировала. И хотя показатели И -6 и С-РБ в процессе мечения высокими дозами ГКС плюс секукинумаб плюс колхицин удацось снизить, Аинамика именно иН/ $\Lambda$ (при поступлении 9,6, через 5 Аней - 31 и еще через 5 Аней - 38,4) наиболее точно коррелировала с прогрессированием коронавирусной пневмонии и указывала на негативный прогноз. Но главным уроком из этого наблюдения является преАположение, что упрежАающая противовоспалительная терапия (к примеру колхицином), особенно в группах высокого риска, Аолжна начинаться как можно раньше, вместе с противовирусным мечением (может быть Ааже на амбуматорном этапе).

\section{Финансирование}

Аанная работа выполнена в рамках государственного задания МНОЦ МГУ имени М. В. Аомоносова.

Статья поступима 18.08.2020

\section{СПИСОК АИТЕРАТУРЫ}

1. Pericàs JM, Hernandez-Meneses M, Sheahan TP, Quintana E, Ambrosioni J, Sandoval E et al. COVID-19: from epidemiology to treatment. European Heart Journal. 2020;41(22):2092-112. DOI: 10.1093/eurheartj/ehaa462

2. Wu Z, McGoogan JM. Characteristics of and Important Lessons From the Coronavirus Disease 2019 (COVID-19) Outbreak in China: Summary of a Report of 72314 Cases From the Chinese Center for Disease Control and Prevention. JAMA. 2020;323(13):1239. DOI: 10.1001/ jama.2020.2648

3. Guan W, Ni Z, Hu Y, Liang W, Ou C, He J et al. Clinical Characteristics of Coronavirus Disease 2019 in China. New England Journal of Medicine. 2020;382(18):1708-20. DOI: 10.1056/NEJMoa2002032

4. Zhang X, Cai H, Hu J, Lian J, Gu J, Zhang $S$ et al. Epidemiological, clinical characteristics of cases of SARS-CoV-2 infection with abnormal imaging findings. International Journal of Infectious Diseases. 2020;94:81-7. DOI: 10.1016/j.ijid.2020.03.040

5. Gao C, Cai Y, Zhang K, Zhou L, Zhang Y, Zhang X et al. Association of hypertension and antihypertensive treatment with COVID-19 mortality: a retrospective observational study. European Heart Journal. 2020;41(22):2058-66. DOI: 10.1093/eurheartj/ehaa433

6. De Spiegeleer A, Bronselaer A, Teo JT, Byttebier G, De Tré G, Belmans L et al. The Effects of ARBs, ACEis, and Statins on Clinical Outcomes of COVID-19 Infection Among Nursing Home Residents. Journal of the American Medical Directors Association. 2020;21 (7):909914.e2. DOI: 10.1016/j.jamda.2020.06.018

7. Bode B, Garrett V, Messler J, McFarland R, Crowe J, Booth R et al. Glycemic Characteristics and Clinical Outcomes of COVID-19 Patients Hospitalized in the United States. Journal of Diabetes Science and Technology. 2020;14(4):813-21. DOI: 10.1177/1932296820924469

8. Mareev V.Yu., Orlova Ya.A., Pavlikova E.P., Matskeplishvili S.T., Akopyan Zh.A., Plisyk A.G. et al. Combination therapy at an early stage of the novel coronavirus infection (COVID-19). Case series and design of the clinical trial "BromhexIne and Spironolactone for CoronavirUs Infection requiring hospiTalization (BISCUIT)”. Kardiologiia. 2020;60(8):4-15. [Russian: Мареев В.Ю., Орлова Я.А., Павмикова Е.П., Мацкеплишвили С.Т., Акопян Ж.А., Пиисюк А.Г. и Ар. Возможности комбинированной терапии на раннем этапе течения новой коронавирусной инфекции (COVID-19). Разбор клинических случаев и Аизайн исследования: Бромгексин И Спиронолактон Амя мечения КоронаВирусной Инфекции, Требующей госпитализации (БИСКВИТ). КарАиология. 2020;60(8):4-15]. DOI: 10.18087/ cardio.2020.8.n1307

9. Muus C, Luecken MD, Eraslan G, Waghray A, Heimberg G, Sikkema L et al. Integrated analyses of single-cell atlases reveal age, gender, and smoking status associations with cell type-specific expression of mediators of SARS-CoV-2 viral entry and highlights inflammatory programs in putative target cells. Bioinformatics. 2020. Av. at: http://biorxiv.org/ lookup/doi/10.1101/2020.04.19.049254.
10. Zayratyants O.V., Samsonova M.V., Mikhaleva L.M., Chernyaev A.L., Mishnev O.D., Krupnov N.M. et al. Pathological anatomy of COVID-19: Atlas. -M.: GBU "NIIOZMM DZM"; 2020. - 140p. [Russian: Зайратьянц О.В., Самсонова М.В., Михамева А.М., Черняев А.. ., Мишнев О.А., Крупнов Н.М. и Ар. Патологическая анатомия COVID-19: Атлас. - М.: ГБУ «НИИОЗММ АЗМ», 2020. 140c.]. ISBN 978-5-907251-57-1

11. Ruan Q, Yang K, Wang W, Jiang L, Song J. Correction to: Clinical predictors of mortality due to COVID-19 based on an analysis of data of 150 patients from Wuhan, China. Intensive Care Medicine. 2020;46(6):1294-7. DOI: 10.1007/s00134-020-06028-z

12. Bradley BT, Maioli H, Johnston R, Chaudhry I, Fink SL, Xu H et al. Histopathology and ultrastructural findings of fatal COVID-19 infections in Washington State: a case series. The Lancet. 2020;396(10247):320-32. DOI: 10.1016/S0140-6736(20)31305-2

13. Hansell DM, Bankier AA, MacMahon H, McLoud TC, Müller NL, Remy J. Fleischner Society: Glossary of Terms for Thoracic Imaging. Radiology. 2008;246(3):697-722. DOI: 10.1148/radiol.2462070712

14. Shimabukuro-Vornhagen A, Gödel P, Subklewe M, Stemmler HJ, Schlößer HA, Schlaak M et al. Cytokine release syndrome. Journal for ImmunoTherapy of Cancer. 2018;6(1):56. DOI: 10.1186/s40425018-0343-9

15. Wang J-Y, Chang S-Y, Huang Y-W, Chang S-C. Serology-positive but minimally symptomatic COVID-19 may still cause lung injury and lung function impairment. The International Journal of Tuberculosis and Lung Disease. 2020;24(6):568-9. DOI: 10.5588/ijtld.20.0197

16. Zhang C, Wu Z, Li J-W, Zhao H, Wang G-Q. Cytokine release syndrome in severe COVID-19: interleukin-6 receptor antagonist tocilizumab may be the key to reduce mortality. International Journal of Antimicrobial Agents. 2020;55(5):105954. DOI: 10.1016/j.ijantimicag.2020.105954

17. Vernadsky R.Yu., Medvedeva A.A., Garbukov E.Yu., Sinilkin I.G., Bragina O.D., Zelchan R.V. et al. Single-photon emission computed tomography with $99 \mathrm{mTc}$-1-thio-d-glucose for metabolic breast cancer imaging. Russian Electronic Journal of Radiology. 2019;9(4):82-96. [Russian: ВернаАский Р.Ю., МеАвеАева А.А., Гарбуков Е.Ю., Синилкин И.Г., Брагина О.А., Зельчан Р.В. и Ар. Метаболическая визуализация рака молочной железы метоАом оАнофотонной эмиссионной компьютерной томографии c 99mTc-1-тио-d-глюкозой. Российский Эмектронный ЖурнаА Иучевой Аиагностики. 2019;9(4):82-96]. DOI: 10.21569/22227415-2019-9-4-82-96

18. Xu Z, Shi L, Wang Y, Zhang J, Huang L, Zhang C et al. Pathological findings of COVID-19 associated with acute respiratory distress syndrome. The Lancet Respiratory Medicine. 2020;8(4):420-2. DOI: 10.1016/S2213-2600(20)30076-X

19. Covid-19 treatment Protocol at MSU Medical center. Av. at: http:// www.mc.msu.ru/protokol-mnoc.pdf. 2020. [Russian: Протокол ме- 
чения COVID-19 Медицинского центра МГУ. 2020. Аоступно на: http://www.mc.msu.ru/protokol-mnoc.pdf ]

20. The OpenSAFELY Collaborative, Williamson E, Walker AJ, Bhaskaran KJ, Bacon S, Bates $\mathrm{C}$ et al. OpenSAFELY: factors associated with COVID-19-related hospital death in the linked electronic health records of 17 million adult NHS patients. Epidemiology. 2020. [Av. at: http://medrxiv.org/lookup/doi/10.1101/2020.05.06.20092999.] DOI: $10.1101 / 2020.05 .06 .20092999$.

21. Guan W, Liang W, Zhao Y, Liang H, Chen Z, Li Y et al. Comorbidity and its impact on 1590 patients with COVID-19 in China: a nationwide analysis. European Respiratory Journal. 2020;55(5):2000547. DOI: $10.1183 / 13993003.00547-2020$

22. Chen G, Wu D, Guo W, Cao Y, Huang D, Wang H et al. Clinical and immunological features of severe and moderate coronavirus disease 2019. Journal of Clinical Investigation. 2020;130(5):2620-9. DOI: 10.1172/ JCI137244

23. Tan L, Kang X, Ji X, Li G, Wang Q, Li Y et al. Validation of Predictors of Disease Severity and Outcomes in COVID-19 Patients: A Descriptive and Retrospective Study. Med. 2020; S2666634020300040. [Epub ahead of print]. DOI: $10.1016 /$ j.medj.2020.05.002

24. Shi H, Han X, Jiang N, Cao Y, Alwalid O, Gu J et al. Radiological findings from 81 patients with COVID-19 pneumonia in Wuhan, China: a descriptive study. The Lancet Infectious Diseases. 2020;20(4):42534. DOI: 10.1016/S1473-3099(20)30086-4

25. Mo X, Jian W, Su Z, Chen M, Peng H, Peng P et al. Abnormal pulmonary function in COVID-19 patients at time of hospital discharge. European Respiratory Journal. 2020;55(6):2001217. DOI: $10.1183 / 13993003.01217-2020$

26. Richardson S, Hirsch JS, Narasimhan M, Crawford JM, McGinn T, Davidson KW et al. Presenting Characteristics, Comorbidities, and Outcomes Among 5700 Patients Hospitalized With COVID-19 in the New York City Area. JAMA. 2020;323(20):2052. DOI: 10.1001/jama.2020.6775

27. Cummings MJ, Baldwin MR, Abrams D, Jacobson SD, Meyer BJ, Balough EM et al. Epidemiology, clinical course, and outcomes of critically ill adults with COVID-19 in New York City: a prospective cohort study. The Lancet. 2020;395(10239):1763-70. DOI: 10.1016/S01406736(20)31189-2

28. Grasselli G, Greco M, Zanella A, Albano G, Antonelli M, Bellani G et al. Risk Factors Associated With Mortality Among Patients With COVID-19 in Intensive Care Units in Lombardy, Italy. JAMA Internal Medicine. 2020;e203539. [Epub ahead of print]. DOI: 10.1001/jamainternmed.2020.3539

29. Mangalmurti N, Hunter CA. Cytokine Storms: Understanding COVID-19. Immunity. 2020;53(1):19-25. DOI: 10.1016/j.immuni.2020.06.017

30. Rizzo P, Vieceli Dalla Sega F, Fortini F, Marracino L, Rapezzi C, Ferrari R. COVID-19 in the heart and the lungs: could we "Notch" the inflammatory storm? Basic Research in Cardiology. 2020;115(3):31. DOI: 10.1007/s00395-020-0791-5

31. Mohan V, Tauseen RA. Spontaneous pneumomediastinum in COVID-19. BMJ Case Reports. 2020;13(5):e236519. DOI: 10.1136/bcr2020-236519

32. Zhou C, Gao C, Xie Y, Xu M. COVID-19 with spontaneous pneumomediastinum. The Lancet Infectious Diseases. 2020;20(4):510. DOI: 10.1016/S1473-3099(20)30156-0

33. Colaneri M, Bogliolo L, Valsecchi P, Sacchi P, Zuccaro V, Brandolino F et al. Tocilizumab for Treatment of Severe COVID-19 Patients: Preliminary Results from SMAtteo COvid19 REgistry (SMACORE). Microorganisms. 2020;8(5):695. DOI: 10.3390/microorganisms8050695

34. Tavazzi G, Pellegrini C, Maurelli M, Belliato M, Sciutti F, Bottazzi A et al. Myocardial localization of coronavirus in COVID-19 cardiogenic shock. European Journal of Heart Failure. 2020;22(5):911-5. DOI: 10.1002/ejhf.1828

35. Baig AM, Khaleeq A, Ali U, Syeda H. Evidence of the COVID-19 Virus Targeting the CNS: Tissue Distribution, Host-Virus Interaction, and Proposed Neurotropic Mechanisms. ACS Chemical Neuroscience. 2020;11(7):995-8. DOI: 10.1021/acschemneuro.0c00122

36. Wunsch H. Mechanical Ventilation in COVID-19: Interpreting the Current Epidemiology. American Journal of Respiratory and Criti- cal Care Medicine. 2020;202(1):1-4. DOI: 10.1164/rccm.2020041385ED

37. Liu J, Liu Y, Xiang P, Pu L, Xiong H, Li C et al. Neutrophil-to-lymphocyte ratio predicts critical illness patients with 2019 coronavirus disease in the early stage. Journal of Translational Medicine. 2020;18(1):206. DOI: $10.1186 / \mathrm{s} 12967-020-02374-0$

38. Imtiaz F, Shafique K, Mirza S, Ayoob Z, Vart P, Rao S. Neutrophil lymphocyte ratio as a measure of systemic inflammation in prevalent chronic diseases in Asian population. International Archives of Medicine. 2012;5(1):2. DOI: 10.1186/1755-7682-5-2

39. Yang A-P, Liu J, Tao W, Li H. The diagnostic and predictive role of NLR, d-NLR and PLR in COVID-19 patients. International Immunopharmacology. 2020;84: 106504. [Epub ahead of print]. DOI: 10.1016/j.intimp.2020.106504

40. Zhang Y, Wu W, Du M, Luo W, Hou W, Shi Y et al. Neutrophil-to-Lymphocyte Ratio may Replace Chest Computed Tomography to Reflect the Degree of Lung Injury in Patients with Corona Virus Disease 2019 (COVID-19). Av. at: https://www.researchsquare.com/article/rs23201/v1. DOI: 10.21203/rs.3.rs-23201/v1.2020.

41. Liu Y, Du X, Chen J, Jin Y, Peng L, Wang HHX et al. Neutrophil-tolymphocyte ratio as an independent risk factor for mortality in hospitalized patients with COVID-19. Journal of Infection. 2020;81(1):e6-12. DOI: 10.1016/j.jinf.2020.04.002

42. Ullah W, Basyal B, Tariq S, Almas T, Saeed R, Roomi S et al. Lymphocyte-to-C-Reactive Protein Ratio: A Novel Predictor of Adverse Outcomes in COVID-19. Journal of Clinical Medicine Research. 2020;12(7):415-22. DOI: $10.14740 /$ jocmr4227

43. Lagunas-Rangel FA. Neutrophil-to-lymphocyte ratio and lymphocyte-to-C-reactive protein ratio in patients with severe coronavirus disease 2019 (COVID-19): A meta-analysis. Journal of Medical Virology. 2020; [Epub ahead of print]. DOI: 10.1002/jmv.25819

44. Ministry of Health of Russian Federation. Temporary methodical recommendations. Medical rehabilitation for new coronavirus infection (COVID-19). Version 2 (31.07.2020). Av. at: https://стопкоронавирус.рф/ai/doc/461/attach/28052020_Preg_COVID-19_vl.pdf. 2020. [Russian: Министерство ЗАравоохранения Российской Федерации. Временные методические рекомендации. Медицинская реабилитация при новой коронавирусной инфекции (COVID-19). Bepсия 2 (31.07.2020). Аоступно на: https://стопкоронавирус.рф/ai/ doc/461/attach/28052020_Preg_COVID-19_v1.pdf]

45. Kewan T, Covut F, Al-Jaghbeer MJ, Rose L, Gopalakrishna KV, Akbik B. Tocilizumab for treatment of patients with severe COVID-19: A retrospective cohort study. EClinicalMedicine. 2020;24: 100418. DOI: 10.1016/j.eclinm.2020.100418

46. Guaraldi G, Meschiari M, Cozzi-Lepri A, Milic J, Tonelli R, Menozzi M et al. Tocilizumab in patients with severe COVID-19: a retrospective cohort study. The Lancet Rheumatology. 2020;2(8):e474-84. DOI: 10.1016/S2665-9913(20)30173-9

47. Somers EC, Eschenauer GA, Troost JP, Golob JL, Gandhi TN, Wang L et al. Tocilizumab for treatment of mechanically ventilated patients with COVID-19. Clinical Infectious Diseases. 2020; ciaa954. [Epub ahead of print]. DOI: $10.1093 / \mathrm{cid} /$ ciaa954

48. Antinori S, Bonazzetti C, Gubertini G, Capetti A, Pagani C, Morena V et al. Tocilizumab for cytokine storm syndrome in COVID-19 pneumonia: an increased risk for candidemia? Autoimmunity Reviews. 2020;19(7):102564. DOI: 10.1016/j.autrev.2020.102564

49. Marfella R, Paolisso P, Sardu C, Bergamaschi L, D’Angelo EC, Barbieri $\mathrm{M}$ et al. Negative impact of hyperglycaemia on tocilizumab therapy in Covid-19 patients. Diabetes \& Metabolism. 2020;S1262363620300823. [Epub ahead of print]. DOI: 10.1016/j.diabet.2020.05.005

50. Roche provides an update on the phase III COVACTA trial of Actem$\mathrm{ra} /$ RoActemra in hospitalised patients with severe COVID-19 associated pneumonia. [Интернет] Available at: https://www.roche.com/investors/updates/inv-update-2020-07-29.htm

51. Parodi E, O'Donnell C. Tocilizumab Fails to Help COVID-19 Patients in Italian Study. The Rheumatologist. 2020; [Av. at: https://www.therheumatologist.org/article/tocilizumab-fails-to-help-covid-19-patients-in-italian-study/] 
52. Roche HL. A Study to Evaluate the Efficacy and Safety of Remdesivir Plus Tocilizumab Compared with Remdesivir Plus Placebo in Hospitalized Participants With Severe COVID-19 Pneumonia (REMDACTA). ClinicalTrials.gov Identifier: NCT04409262. [Интернет] Available at: https://clinicaltrials.gov/ct2/show/NCT04409262

53. Hoffmann-La Roche. A Phase-II, Open-Label, Randomized, Multicenter Study to Investigate the Pharmacodynamics, Pharmacokinetics, Safety, and Efficacy of $8 \mathrm{mg} / \mathrm{kg}$ or $4 \mathrm{mg} / \mathrm{kg}$ Intravenous Tocilizumab in Patients with Moderate to Severe COVID-19 Pneumonia (MARIPOSA). ClinicalTrials.gov Identifier: NCT04363736. Av. at: https:// clinicaltrials.gov/ct2/show/NCT04363736.2020 г.

54. Genentech, Inc. A Randomized, Double-Blind, Placebo-Controlled, Multicenter Study to Evaluate the Efficacy and Safety of Tocilizumab in Hospitalized Patients With COVID-19 Pneumonia. ClinicalTrials.gov Identifier: NCT04372186. Av. at: https://clinicaltrials.gov/ct2/show/ NCT04372186. 2020 r.

55. Mareev V.Yu., Orlova Ya.A., Pavlikova E.P., Matskeplishvili S.T., Krasnova T.N., Malahov P.S. et al. Steroid pulse -therapy in patients with coronAvirus Pneumonia (COVID-19), sYstemic inFlammation And Risk of vEnous thRombosis and thromboembolism (WAYFARER Study). Kardiologiia. 2020;60(6):15-29. [Russian: Мареев В.Ю., Ормова Я.А., Павликова Е.П., Мацкеплишвили С.Т., Краснова Т.Н., Малахов П.С. и Ар. Пульс-терапия стероидными гормонами больных с коронавирусной пневмонией (COVID-19), системным воспалением и риском венозных тромбозов и тромбоэмболий (исследование ПУТНИК). КарАиомогия. 2020;60(6):15-29]. DOI: 10.18087/cardio.2020.6.n1226

56. The RECOVERY Collaborative Group, Horby P, Lim WS, Emberson JR, Mafham M, Bell JL et al. Dexamethasone in Hospitalized Patients with Covid-19 - Preliminary Report. New England Journal of Medicine. 2020; NEJMoa2021436. [Epub ahead of print]. DOI: 10.1056/NEJMoa2021436

57. Ramiro S, Mostard RLM, Magro-Checa C, van Dongen CMP, Dormans T, Buijs J et al. Historically controlled comparison of glucocorticoids with or without tocilizumab versus supportive care only in patients with COVID-19-associated cytokine storm syndrome: results of the CHIC study. Annals of the Rheumatic Diseases. 2020;79(9):1143-51. DOI: 10.1136/annrheumdis-2020-218479

58. Sinha P, Matthay MA, Calfee CS. Is a "Cytokine Storm" Relevant to COVID-19? JAMA Internal Medicine. 2020; [Epub ahead of print]. DOI: 10.1001/jamainternmed.2020.3313

59. Huang C, Wang Y, Li X, Ren L, Zhao J, Hu Y et al. Clinical features of patients infected with 2019 novel coronavirus in Wuhan, China. The Lancet. 2020;395(10223):497-506. DOI: 10.1016/S01406736(20)30183-5

60. Zhou F, Yu T, Du R, Fan G, Liu Y, Liu Z et al. Clinical course and risk factors for mortality of adult inpatients with COVID-19 in Wuhan, China: a retrospective cohort study. The Lancet. 2020;395(10229):1054-62. DOI: 10.1016/S0140-6736(20)30566-3

61. Zhang L, Yan X, Fan Q, Liu H, Liu X, Liu Z et al. D-dimer levels on admission to predict in-hospital mortality in patients with Covid-19. Journal of Thrombosis and Haemostasis. 2020;18(6):1324-9. DOI: 10.1111/jth.14859

62. Tang N, Bai H, Chen X, Gong J, Li D, Sun Z. Anticoagulant treatment is associated with decreased mortality in severe coronavirus disease 2019 patients with coagulopathy. Journal of Thrombosis and Haemostasis. 2020;18(5):1094-9. DOI: 10.1111/jth.14817

63. Wichmann D, Sperhake J-P, Lütgehetmann M, Steurer S, Edler C, Heinemann A et al. Autopsy Findings and Venous Thromboembolism in Patients With COVID-19: A Prospective Cohort Study. Annals of Internal Medicine. 2020;173(4):268-77. DOI: 10.7326/M20-2003

64. Paranjpe I, Fuster V, Lala A, Russak AJ, Glicksberg BS, Levin MA et al. Association of Treatment Dose Anticoagulation With In-Hospital Survival Among Hospitalized Patients With COVID-19. Journal of the American College of Cardiology. 2020;76(1):122-4. DOI: 10.1016/j. jacc.2020.05.001

65. Klok FA, Kruip MJHA, van der Meer NJM, Arbous MS, Gommers DAMPJ, Kant KM et al. Incidence of thrombotic complications in critically ill ICU patients with COVID-19. Thrombosis Research. 2020; 191:145-7. DOI: 10.1016/j.thromres.2020.04.013
66. Soylu K, Gedikli Ö, Ekşi A, Avcıŏlu Y, Soylu Aİ, Yüksel S et al. Neutrophil-to-lymphocyte ratio for the assessment of hospital mortality in patients with acute pulmonary embolism. Archives of Medical Science. 2016; 1:95-100. DOI: 10.5114/aoms.2016.57585

67. Price LC, McCabe C, Garfield B, Wort SJ. Thrombosis and COVID-19 pneumonia: the clot thickens! European Respiratory Journal. 2020;56(1):2001608. DOI: 10.1183/13993003.01608-2020

68. Klok FA, Kruip MJHA, van der Meer NJM, Arbous MS, Gommers D, Kant KM et al. Confirmation of the high cumulative incidence of thrombotic complications in critically ill ICU patients with COVID-19: An updated analysis. Thrombosis Research. 2020; 191:148-50. DOI: $10.1016 /$ j.thromres.2020.04.041

69. Lodigiani C, Iapichino G, Carenzo L, Cecconi M, Ferrazzi P, Sebastian T et al. Venous and arterial thromboembolic complications in COVID-19 patients admitted to an academic hospital in Milan, Italy. Thrombosis Research. 2020;191:9-14. DOI: 10.1016/j.thromres.2020.04.024

70. Criel M, Falter M, Jaeken J, Van Kerrebroeck M, Lefere I, Meylaerts L и ар. Venous thromboembolism in SARS-CoV-2 patients: only a problem in ventilated ICU patients, or is there more to it? European Respiratory Journal. 2020;56(1):2001201. DOI: 10.1183/13993003.01201-2020

71. Middeldorp S, Coppens M, Haaps TF, Foppen M, Vlaar AP, Müller MCA et al. Incidence of venous thromboembolism in hospitalized patients with COVID-19. Journal of Thrombosis and Haemostasis. 2020;18(8):1995-2002. DOI: 10.1111/jth.14888

72. Ackermann M, Verleden SE, Kuehnel M, Haverich A, Welte T, Laenger $\mathrm{F}$ et al. Pulmonary Vascular Endothelialitis, Thrombosis, and Angiogenesis in Covid-19. New England Journal of Medicine. 2020;383(2):120-8. DOI: 10.1056/NEJMoa2015432

73. Bryce C, Grimes Z, Pujadas E, Ahuja S, Beasley MB, Albrecht R et al. Pathophysiology of SARS-CoV-2: targeting of endothelial cells renders a complex disease with thrombotic microangiopathy and aberrant immune response. The Mount Sinai COVID-19 autopsy experience. Pathology. 2020. Av. at: https://www.medrxiv.org/content/10.1101/202 0.05.18.20099960v1.

74. McGonagle D, O’Donnell JS, Sharif K, Emery P, Bridgewood C. Immune mechanisms of pulmonary intravascular coagulopathy in COVID-19 pneumonia. The Lancet Rheumatology. 2020;2(7):e437-45. DOI: 10.1016/S2665-9913(20)30121-1

75. Dorward DA, Russell CD, Um IH, Elshani M, Armstrong SD, PenriceRandal $R$ et al. Tissue-specific tolerance in fatal Covid-19. Infectious Diseases (except HIV/AIDS). 2020. Av. at: https://www.medrxiv.org/ content/10.1101/2020.07.02.20145003v1.

76. Iba T, Levi M, Levy JH. Sepsis-Induced Coagulopathy and Disseminated Intravascular Coagulation. Seminars in Thrombosis and Hemostasis. 2020;46(01):089-95. DOI: 10.1055/s-0039-1694995

77. Connors JM, Levy JH. COVID-19 and its implications for thrombosis and anticoagulation. Blood. 2020;135(23):2033-40. DOI: 10.1182/ blood.2020006000

78. Panigada M, Bottino N, Tagliabue P, Grasselli G, Novembrino C, Chantarangkul V et al. Hypercoagulability of COVID-19 patients in intensive care unit: A report of thromboelastography findings and other parameters of hemostasis. Journal of Thrombosis and Haemostasis. 2020;18(7):1738-42. DOI: $10.1111 /$ jth. 14850

79. Tang N, Li D, Wang X, Sun Z. Abnormal coagulation parameters are associated with poor prognosis in patients with novel coronavirus pneumonia. Journal of Thrombosis and Haemostasis. 2020;18(4):844-7. DOI: $10.1111 /$ jth. 14768

80. Oudkerk M, Büller HR, Kuijpers D, van Es N, Oudkerk SF, McLoud TC et al. Diagnosis, Prevention, and Treatment of Thromboembolic Complications in COVID-19: Report of the National Institute for Public Health of the Netherlands. Radiology. 2020;201629. [Epub ahead of print]. DOI: 10.1148/radiol.2020201629

81. Llitjos J, Leclerc M, Chochois C, Monsallier J, Ramakers M, Auvray M et al. High incidence of venous thromboembolic events in anticoagulated severe COVID-19 patients. Journal of Thrombosis and Haemostasis. 2020;18(7):1743-6. DOI: $10.1111 /$ jth.14869

82. Gavioli EM, Sikorska G, Man A, Rana J, Vider E. Current Perspectives of Anticoagulation in Patients with COVID-19. Journal of Car- 
diovascular Pharmacology. 2020;76(2):146-50. DOI: 10.1097/ FJC.0000000000000861

83. Wise J. Covid-19 and thrombosis: what do we know about the risks and treatment? BMJ. 2020;369:m2058. DOI: 10.1136/bmj.m2058

84. Wang T, Chen R, Liu C, Liang W, Guan W, Tang R et al. Attention should be paid to venous thromboembolism prophylaxis in the management of COVID-19. The Lancet Haematology. 2020;7(5): e362-3. DOI: $10.1016 /$ S2352-3026(20)30109-5

85. Spyropoulos AC, Ageno W, Barnathan ES. Hospital-based use of thromboprophylaxis in patients with COVID-19. The Lancet. 2020;395(10234):e75. DOI: 10.1016/S0140-6736(20)30926-0

86. Bikdeli B, Madhavan MV, Jimenez D, Chuich T, Dreyfus I, Driggin E et al. COVID-19 and Thrombotic or Thromboembolic Disease: Implications for Prevention, Antithrombotic Therapy, and Follow-Up. Journal of the American College of Cardiology. 2020;75(23):2950-73. DOI: $10.1016 /$ j.jacc.2020.04.031

87. Berghe TV, Linkermann A, Jouan-Lanhouet S, Walczak H, Vandenabeele P. Regulated necrosis: the expanding network of non-apoptotic cell death pathways. Nature Reviews Molecular Cell Biology. 2014;15(2):135-47. DOI: $10.1038 / \mathrm{nrm} 3737$

88. Jorgensen I, Miao EA. Pyroptotic cell death defends against intracellular pathogens. Immunological Reviews. 2015;265(1):130-42. DOI: 10.1111/imr.12287

89. Franchi L, Eigenbrod T, Muñoz-Planillo R, Nuñez G. The inflammasome: a caspase-1-activation platform that regulates immune responses and disease pathogenesis. Nature Immunology. 2009;10(3):241-7. DOI: $10.1038 /$ ni.1703

90. Velazquez-Salinas L, Verdugo-Rodriguez A, Rodriguez LL, Borca MV. The Role of Interleukin 6 During Viral Infections. Frontiers in Microbiology. 2019;10:1057. DOI: 10.3389/fmicb.2019.01057

91. Han H, Ma Q, Li C, Liu R, Zhao L, Wang W et al. Profiling serum cytokines in COVID-19 patients reveals IL- 6 and IL-10 are disease severity predictors. Emerging Microbes \& Infections. 2020;9(1):1123-30. DOI: $10.1080 / 22221751.2020 .1770129$

92. Bulat V, Situm M, Azdajic MD, Likic R. Potential role of IL-17 blocking agents in the treatment of severe COVID-19? British Journal of Clinical Pharmacology. 2020; bcp.14437. [Epub ahead of print]. DOI: 10.1111/bcp. 14437

93. Feldmann M, Maini RN, Woody JN, Holgate ST, Winter G, Rowland M et al. Trials of anti-tumour necrosis factor therapy for COVID-19 are urgently needed. The Lancet. 2020;395(10234):1407-9. DOI: 10.1016/S0140-6736(20)30858-8

94. Ucciferri C, Auricchio A, Di Nicola M, Potere N, Abbate A, Cipollone $\mathrm{F}$ et al. Canakinumab in a subgroup of patients with COVID-19. The Lancet Rheumatology. 2020;2(8):e457-ee458. DOI: 10.1016/ S2665-9913(20)30167-3

95. Ridker PM, Everett BM, Thuren T, MacFadyen JG, Chang WH, Ballantyne $\mathrm{C}$ et al. Antiinflammatory Therapy with Canakinum$\mathrm{ab}$ for Atherosclerotic Disease. New England Journal of Medicine. 2017;377(12):1119-31. DOI: 10.1056/NEJMoa1707914

96. Ministry of Health of Russian Federation. Temporary guidelines of the Ministry of health of the Russian Federation "Prevention, diagnosis and treatment of new coronavirus infection (COVID-19)". Version 4 of 27.03.2020. Moscow. Av. at: https://static-3.rosminzdrav.ru/system/attachments/attaches/000/049/877/original/COVID19_recomend_v4.pdf. 2020. [Russian: Министерство зАравоохранения РФ. Временные методические рекомендации «Профикактика, Аиагностика и мечение новой коронавирусной инфекции (COVID-19)». Версия 4 (27.03.2020). Москва. Аоступно на: https://static-3.rosminzdrav.ru/system/attachments/attaches/000/049/877/original/COVID19_recomend_v4.pdf]

97. Cao Y, Wei J, Zou L, Jiang T, Wang G, Chen L et al. Ruxolitinib in treatment of severe coronavirus disease 2019 (COVID-19): A multicenter, single-blind, randomized controlled trial. Journal of Allergy and Clinical Immunology. 2020;146(1):137-146.e3. DOI: 10.1016/j.jaci.2020.05.019
98. Beringer A, Miossec P. Systemic effects of IL-17 in inflammatory arthritis. Nature Reviews Rheumatology. 2019;15(8):491-501. DOI: 10.1038/s41584-019-0243-5

99. Miossec P, Kolls JK. Targeting IL-17 and TH17 cells in chronic inflammation. Nature Reviews Drug Discovery. 2012;11(10):763-76. DOI: $10.1038 / \mathrm{nrd} 3794$

100. Schett G, Sticherling M, Neurath MF. COVID-19: risk for cytokine targeting in chronic inflammatory diseases? Nature Reviews Immunology. 2020;20(5):271-2. DOI: 10.1038/s41577-020-0312-7

101. Carugno A, Gambini DM, Raponi F, Vezzoli P, Locatelli AGC, Di Mercurio $\mathrm{M}$ et al. COVID-19 and biologics for psoriasis: A high-epidemic area experience - Bergamo, Lombardy, Italy. Journal of the American Academy of Dermatology. 2020;83(1):292-4. DOI: 10.1016/j.jaad.2020.04.165

102. Di Lernia V, Bombonato C, Motolese A. COVID-19 in an elderly patient treated with secukinumab. Dermatologic Therapy. 2020;e13580. [Epub ahead of print]. DOI: 10.1111/dth.13580

103. Dagenais M, Skeldon A, Saleh M. The inflammasome: in memory of Dr. Jurg Tschopp. Cell Death \& Differentiation. 2012;19(1):5-12. DOI: $10.1038 /$ cdd.2011.159

104. Jamilloux Y, Henry T, Belot A, Viel S, Fauter M, El Jammal T et al. Should we stimulate or suppress immune responses in COVID-19? Cytokine and anti-cytokine interventions. Autoimmunity Reviews. 2020;19(7):102567. DOI: 10.1016/j.autrev.2020.102567

105. Clancy CJ, Nguyen MH. Coronavirus Disease 2019, Superinfections, and Antimicrobial Development: What Can We Expect? Clinical Infectious Diseases. 2020; ciaa524. [Epub ahead of print]. DOI: 10.1093/ cid/ciaa524

106. FitzGerald JD, Dalbeth N, Mikuls T, Brignardello-Petersen R, Guyatt G, Abeles AM et al. 2020 American College of Rheumatology Guideline for the Management of Gout. Arthritis Care \& Research. 2020;72(6):744-60. DOI: $10.1002 /$ acr.24180

107. TardifJ-C, Kouz S, Waters DD, Bertrand OF, Diaz R, Maggioni AP et al. Efficacy and Safety of Low-Dose Colchicine after Myocardial Infarction. New England Journal of Medicine. 2019;381(26):2497-505. DOI: $10.1056 /$ NEJMoa1912388

108. Martínez GJ, Celermajer DS, Patel S. The NLRP3 inflammasome and the emerging role of colchicine to inhibit atherosclerosis-associated in flammation. Atherosclerosis. 2018; 269:262-71. DOI: 10.1016/j.atherosclerosis.2017.12.027

109. Lu Y, Chen J, Xiao M, Li W, Miller DD. An Overview of Tubulin Inhibitors That Interact with the Colchicine Binding Site. Pharmaceutical Research. 2012;29(11):2943-71. DOI: 10.1007/s11095-012-0828-z

110. Deftereos SG, Giannopoulos G, Vrachatis DA, Siasos GD, Giotaki SG, Gargalianos P et al. Effect of Colchicine vs Standard Care on Cardiac and Inflammatory Biomarkers and Clinical Outcomes in Patients Hospitalized with Coronavirus Disease 2019: The GRECCO-19 Randomized Clinical Trial. JAMA Network Open. 2020;3(6): e2013136. DOI: 10.1001/jamanetworkopen.2020.13136

111. Montreal Heart Institute. Colchicine Coronavirus SARS-CoV2 Trial (COLCORONA) (COVID-19). ClinicalTrials.gov Identifier: NCT04322682. [Интернет] Available at: https://clinicaltrials.gov/ ct2/show/NCT04322682

112. Population Health Research Institute. The ECLA PHRI COLCOVID Trial. Effects of Colchicine on Moderate/High-risk Hospitalized COVID-19 Patients. (COLCOVID). ClinicalTrials.gov Identifier: NCT04328480. [Интернет] Available at: https://clinicaltrials.gov/ ct2/show/NCT04328480

113. Lomonosov Moscow State University Medical Research and Educational Center. COLchicine Versus Ruxolitinib and Secukinumab In Open Prospective Randomized Trial (COLORIT). ClinicalTrials.gov Identifier: NCT04403243. Av. at: https://clinicaltrials.gov/ct2/show/ NCT04403243.2020 г.

114. Carfi A, Bernabei R, Landi F, for the Gemelli Against COVID-19 Post-Acute Care Study Group. Persistent Symptoms in Patients After Acute COVID-19. JAMA. 2020;324(6):603-5. DOI: 10.1001/jama.2020.12603 